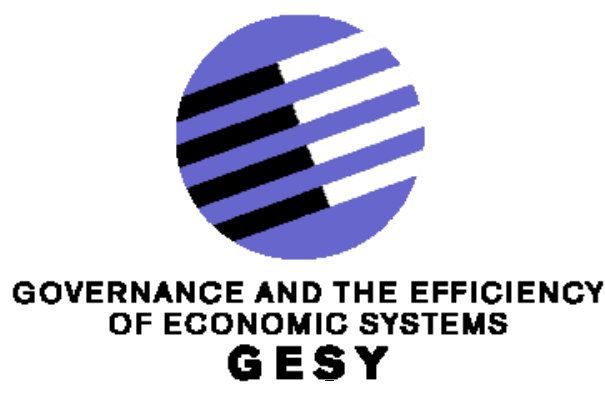

Discussion Paper No. 419

\title{
Endogenous group formation in experimental contests
}

\author{
Luisa Herbst * \\ Kai A Konrad ** \\ Florian Morath $* * *$
}

* Max Planck Institute for Tax Law and Public Finance, Munich and Social Science Research Center Berlin

** Max Planck Institute for Tax Law and Public Finance, Munich

*** Max Planck Institute for Tax Law and Public Finance, Munich

April 2013

Financial support from the Deutsche Forschungsgemeinschaft through SFB/TR 15 is gratefully acknowledged.

Sonderforschungsbereich/Transregio $15 \cdot$ www.sfbtr15.de

Universität Mannheim · Freie Universität Berlin · Humboldt-Universität zu Berlin · Ludwiq-Maximilians-Universität München Rheinische Friedrich-Wilhelms-Universität Bonn · Zentrum für Europäische Wirtschaftsforschung Mannheim 


\title{
Endogenous group formation in experimental contests *
}

\author{
Luisa Herbst Kai A. Konrad Florian Morath ${ }^{\dagger}$
}

April 22, 2013

\begin{abstract}
We study endogenous group formation in tournaments employing experimental three-player contests. We find that players in endogenously formed alliances cope better with the moral hazard problem in groups than players who are forced into an alliance. Also, players who are committed to expending effort above average choose to stand alone. If these players are forced to play in an alliance, they invest even more, whereas their co-players choose lower effort. Anticipation of this exploitation may explain their preference to stand alone.
\end{abstract}

JEL codes: D72, D74

Keywords: Endogenous group formation, contest, conflict, alliance, experiment, moral hazard problem, free-riding, in-group favoritism

\footnotetext{
*We thank Alessandra Casella, Bruno Frey, Werner Güth, Changxia Ke, Martin Kocher, Sandra Ludwig, Roman Sheremeta as well as seminar participants at Berlin, Exeter, Jena, and Munich for helpful comments. Moreover, we thank MELESSA of the University of Munich for providing laboratory resources and gratefully acknowledge financial support from the German Research Foundation (DFG, grant no. SFB-TR-15).

${ }^{\dagger}$ Max Planck Institute for Tax Law and Public Finance, Department of Public Economics, Marstallplatz 1, 80539 Munich, Germany. Herbst: luisa.herbst@tax.mpg.de; Konrad: kai.konrad@tax.mpg.de; Morath: florian.morath@tax.mpg.de.
} 


\section{Introduction}

This paper analyzes the determinants of group formation and its consequences for efforts and success in a conflict framework of competition between a group of players (an 'alliance') and an opponent. Which characteristics determine whether a player enters into an alliance or prefers to stand alone in an upcoming contest? How does the process of alliance formation affect contest behavior and what are the implications of alliance formation on the players' effort contributions and payoffs? Our paper provides answers to these questions and offers insights that are useful for the institutional design in situations where rewards are allocated on the basis of relative performance.

For anecdotal evidence on possible answers to the questions outlined we can resort to classic fiction. In his drama Wilhelm Tell, Friedrich Schiller (1804) describes the formation of an alliance as well as the conscious decision to abstain from joining an alliance, both for good economic reasons. First, the drama features the famous "Rütli-Oath" in which three men unite forces in an alliance to fight against tyranny. It refers to the legend according to which three cantons formed a confederation that developed into what is Switzerland today. Their oath is their mutual promise to act collectively and to jointly pursue a common interest, making reference to a common history and family roots ("Yet are we but one race, born of one blood, And all are children of one common home"). This indirectly hints at a recognition of the general problem of moral hazard in teams and appeals to the role of group spirit and in-group favoritism for overcoming the moral hazard problem. Second, as the benefits of alliance formation can be asymmetric, we may expect that players who would contribute a disproportionately large share in the alliance prefer to stand alone. Wilhelm Tell himself, the protagonist of the drama, behaves according to this principle. When Stauffacher argues that "even the weak grow strong by union", Tell counters the argument by claiming: "But the strong man is the strongest when alone", and refuses to join the alliance.

Our framework builds on tournament theory where the reward scheme depends on relative performance. Tournaments or contests are frequently used in organizations to incentivize and motivate employees; the seminal paper on tournaments in labor markets is Lazear and Rosen (1981). It analyzes exogenously given tournament structures; one process that determines the tournament structure is the possibility of alliance formation. In many sectors, team formation in the workplace has become increasingly popular. ${ }^{1}$ Moreover, the competition

\footnotetext{
${ }^{1}$ The implementation of self-managed work teams can lead to productivity increases (see Lazear and Shaw 2007 for a discussion of the organization of work teams and the prevalence of teamwork). There is also anecdotal evidence of companies that have benefitted from allowing their employees to initiate team formation (Wall Street Journal, 13 August 2007, How a Company Made Everyone a Team Player, http://online.wsj.com/article/SB118696661138495617.html).
} 
with other individuals or teams, such as in the context of sales or product development teams, can have an important effect on group cohesion and the incentive problem within the team. If several players form a team, this group formation adds a problem of moral hazard in teams to the tournament: an individual member's effort benefits all members of his group. This positive externality has received considerable attention (Olson and Zeckhauser 1966, Holmstrom 1982). If the group competes with an out-group, an individual member's effort also has a negative externality as it harms members of the competing group. These externalities and the collective action problem make it difficult to explain why alliances are formed voluntarily. Economists recognized the formation of an alliance as a puzzle. In order to explain the formation of alliances they resorted to technological benefits of fighting in an alliance (Skaperdas 1998, Kovenock and Roberson 2012), while political scientists explain alliance formation with deterrence effects and balancing behavior (Gulick 1955, Morgenthau 1963, Waltz 1979, Sorokin 1994) as a means to avoid violent conflict or to end it more quickly.

As indicated by psychologists, the existence of an out-group can have an important effect on the emergence of in-group solidarity. Members of a group may develop a 'feeling to belong' to a group and their behavior may show in-group favoritism and spiteful attitudes towards the out-group. ${ }^{2}$ These motivations exist even if individuals are exogenously grouped together. Allowing individuals to choose whether or not to form a team can affect the strength of the 'feeling to belong' and may have an impact on the individuals' contributions to team effort. It also generates selection effects. For instance, students are often allowed to submit their homework in groups. However, when forming such study groups and deciding on their own contribution, they have to take into account what the other students' willingness to form groups might tell them about their characteristics. Just as the example of Wilhelm Tell suggests, such selection effects together with the implications on individual choices and group cohesion are salient features of alliance formation in contests.

We analyze moral hazard in groups and self-selection into alliances in a controlled laboratory experiment in which players choose whether or not to enter into an alliance and how much effort to expend in the contest with an out-group. The framework that we have chosen can be considered the generic framework to study alliance formation in the theory of conflict. Three players compete for a prize of a given size according to the rules of a Tullock (1980) contest, which is a frequently analyzed type of tournament. ${ }^{3}$ Prior to this competi-

\footnotetext{
${ }^{2}$ See, e.g., Sherif et al. (1961), Tajfel and Turner (1979), Tajfel (1982). There is also evidence from biology, and evolutionary game theory can explain such behavior (see, e.g., Maynard Smith 1974 and, for more recent contributions, Eaton at el. 2011 and Konrad and Morath 2012).

${ }^{3}$ Alliances in contests have been extensively studied by theorists, see Ursprung (1990), Nitzan (1991), Baik and Lee (2001), Esteban and Sákovics (2003), Konrad and Kovenock (2009), Kovenock and Roberson (2012), and, for a survey, Konrad (2011).
} 
tion, two of these players are given the opportunity to join forces and form an alliance. ${ }^{4}$ We focus on the implications of an alliance being an association that is based on a conscious voluntary choice, compared to a framework in which the alliance is exogenously imposed. In a purely consequentialist approach with symmetric players who are exclusively concerned with their monetary payoffs, the actual procedure that leads to an alliance cannot make a difference. However, procedures can matter, and voluntary alliance formation, compared to exogenously imposed alliance play, may make a difference. If players care for aspects other than monetary payoffs, voluntary choice for or against an alliance can induce selection effects. This may drive players' expectations about what types of players they are likely to be matched with if they choose to enter into an alliance, and what efforts their co-players would expend. Moreover, the procedural aspect and the active commitment to fight jointly may induce behavioral effects. It may strengthen the 'feeling to belong' if the alliance is the outcome of a voluntary choice, compared to exogenously formed alliances; this group spirit may induce stronger in-group favoritism. Again, this may be anticipated and consequently influence selection and cause behavioral reactions by other players.

To identify and isolate these potential effects we compare interaction in a contest across treatments with exogenous alliances and endogenous alliances where the outside option is stand-alone play and where the out-group is always represented by one further player. We track an individual's behavior in environments in which the individual does not have a choice, but has to act as alliance player and stand-alone player, respectively. The effort choices in these "NO CHOICE" contests can then be related to their preferences on whether to form an alliance or to stand alone. Moreover, the data on exogenous alliances provide the benchmark against which we compare the behavior of endogenously formed alliances.

Some of the key findings are as follows: Voluntary formation of an alliance is a frequent outcome, even in situations in which players pay to enter into an alliance. Strong players, however, have a preference for acting as stand-alone players, where "strong players" are players who are committed to expend high effort due to, for instance, a higher subjective value of winning the contest. Because of the public good nature of individual contributions to alliance effort, strong players are "exploited" by their alliance partner when entering into an alliance. Moreover, those "strong players" get a higher expected payoff in the stand-alone contest. This explains their preference for standing alone and is much in line with Wilhelm Tell's point of view. We also find that alliances which emerge from a voluntary choice of the players mobilize significantly more contest effort than exogenously formed alliances. The

\footnotetext{
${ }^{4}$ The theory of alliance formation in contests has been considered, for instance, by Skaperdas (1998), Garfinkel (2004), Bloch et al. (2006), Sanchez-Pages (2007a,b), and Tan and Wang (2010). A recent survey of the literature is Bloch (2012).
} 
moral hazard in teams is weakened if team formation is an endogenous process.

Empirically, alliances and their formation and resolution in conflicts have been studied by political scientists in the field of international relations, using the ATOP (Alliance Treaty Obligations and Provisions Project) and the COW (Correlates of War) data sets. ${ }^{5}$ Precise answers on the questions we address are difficult to extract from these data for a number of reasons. First, each international conflict has a number of idiosyncratic aspects. Moreover, international conflict typically does not emerge as a singular event, but is embedded in a specific historical context. Often, a conflict cannot be understood or interpreted without reference to preceding conflict.

Within experimental economics, there is a growing literature that studies contests as well as the interaction of contestants in groups against groups or against individuals, where the groups are exogenously imposed on subjects (see, e.g., Nalbantian and Schotter 1997 for an early experiment and Sutter and Strassmair 2009, Abbink et al. 2010, Sheremeta and Zhang 2010, Ahn et al. 2011, Cherry and Cotten 2011, and Cason et al. 2012 for more recent contributions; an excellent and comprehensive survey is Dechenaux et al. 2012). ${ }^{6}$ In a complex, dynamic experiment, Smith et al. (2012) analyze the impact of group formation on efficiency "in anarchy" where subjects can invest in production, expropriation and defense. Cherry et al. (2013) study the effects of investment cost, group size and group formation on contributions to a group public good in a framework where contributions reduce total output available. They find that individuals tend to vote for the socially optimal group size, which is determined by the trade-off between the effects of individual investment on group effort and on total output. Choices to form groups have also been analyzed by Benenson et al. (2009) wherein coalition formation with up to two fictional opponents changes the (exogenously determined) probability of winning a prize. They find that relative power matters for coalition formation and that coalitions are more often formed with opponents called "friends". We are not aware of any other experimental group contest in which groups form endogenously and which is used to study the effect of endogenizing group formation as well as the question of which type of player self-selects into the alliance and which type prefers to stand alone. ${ }^{7}$

\footnotetext{
${ }^{5}$ See Kimball (2006) and references therein. According to these, alliance formation increases with the number of shared rivals, with the homogeneity of power and the similarity of the political system (democratic versus autocratic states).

${ }^{6}$ This literature also analyzes multi-stage contests (Parco et al. 2005; Amaldoss and Rapoport 2005, 2009; Amegashie et al. 2007; Sheremeta 2010a; Chark et al. 2011; Altmann et al. 2012; Ke et al. 2012, 2013). Ke et al. (2012, 2013) examine three-player contests in a structurally related environment with exogenously imposed alliances, focusing, however, on the impact of potential internal conflict inside victorious alliances.

${ }^{7}$ In the context of contests between individuals, endogenous entry into tournaments and self-selection effects have been studied, for instance, by Eriksson et al. (2009), Cason et al. (2010), Dohmen and Falk (2011), and Morgan et al. (2012).
} 
While the role of endogeneity for the moral hazard problem is seemingly unexplored in experimental contests, endogenous group formation has attracted attention in a different area of economic experiments: public goods games. The first paper on endogenous group formation in a public goods experiment is Ehrhart and Keser (1999), followed by a large number of recent contributions to this field. A focus of these studies has been on the impact of different institutional rules and mechanisms on the resulting group size and level of contributions, for instance, the role of entry and exit rules (Ahn et al. 2008 and 2009, Charness and Yang 2011, Aimone et al. forthcoming), minimum contribution levels (e.g., Dannenberg et al. 2010) or punishment opportunities (e.g., Page et al. 2005, Sutter et al. 2010); and endogenous group formation has been shown to increase cooperation (Keser and Montmarquette 2011). Being interested in the stability of the groups formed or the selection of conditional cooperators into the groups, all of these experiments use fixed partner matching. Our contribution to this literature is to study group formation and contributions to a group-specific public good in the presence of an opponent out-group. This feature may have an important effect on individual behavior, even in our random matching design, that is, in the absence of repeated interaction.

Our experiment is also related to the literature on in-group favoritism, which emanated from social psychology (Sherif et al. 1961, Brewer 1979). In our contest framework of competition with an out-group, group coherence and group spirit might be stronger if players self-select into the alliance. This phenomenon of in-group bias, or group solidarity, and its implications on economic outcomes have been analyzed and documented in a variety of different economic interactions: for instance, prisoner's dilemma and battle of the sexes (Charness et al. 2007), minimum effort games (Chen and Chen 2011), dictator and response games (Chen and Li 2009), market experiments (Li et al. 2011) and investment decisions (Sutter 2009). ${ }^{8}$ Most findings in this literature support the emergence of in-group solidarity in social interactions, especially if group membership is made salient. Our experimental contest varies the salience of group membership by either exogenously imposing group formation onto subjects or allowing subjects to voluntarily form groups.

\footnotetext{
${ }^{8}$ Subjects in these experiments were in most cases either randomly assigned into groups ('minimal groups') or divided according to their preferences over paintings. Goette et al. (2012a,b) analyze a prisoner's dilemma game with punishment opportunities, using randomly assigned groups which have built social ties from real social interactions over a certain time period. Other naturally occurring group identities (tribes) are utilized by Bernhard et al. (2006) for instance; Shayo and Zussman (2011) also use ethnic group membership and document in-group bias in a field experiment.
} 


\section{Theoretical and experimental framework}

\subsection{Theoretical framework}

Alliance formation and contest behavior are analyzed in two versions of a two-stage game with three players $A, B$, and $C$. In the first stage, a decision will be made about whether players $A$ and $B$ act in an alliance or as stand-alone players; the two versions differ in whether this decision is made exogenously ( $N O$ CHOICE environment) or endogenously (CHOICE environment), as described below. In the second stage, the three players interact in a contest: Here, each player $i \in\{A, B, C\}$ chooses an effort $x_{i} \geq 0$ that involves a cost which is equal to the effort itself.

Depending on whether or not players $A$ and $B$ are in an alliance in the subgame in stage 2, this subgame is a contest between the alliance of players $A$ and $B$ and the out-group player $C$ (the "2-1" contest) or a symmetric three-player Tullock (1980) lottery contest (the "1-1-1" contest). In the "2-1" contest, the probability that the alliance of $A$ and $B$ wins is equal to the share of $x_{A}+x_{B}$ in total effort $x_{A}+x_{B}+x_{C}$. In the "1-1-1" contest, a player $i$ 's probability of winning is equal to the share of his own effort $x_{i}$ in total effort $x_{A}+x_{B}+x_{C}$, for $i \in\{A, B, C\}$.

The equilibrium predictions for both subgames are given in Appendix A.1. If $A$ and $B$ form an alliance, their joint equilibrium effort in the subsequent "2-1" contest is only half of what they would jointly expend in a three-player stand-alone contest (the "1-1-1" contest); moreover, in equilibrium, the joint win probability for $A$ and $B$ in "2-1" is lower than in "1-1-1". However, the reduction from three to two contesting parties reduces the intensity of the conflict, and the lower effort costs just counterbalance the effect of the free-riding problem that an alliance faces. Overall, the expected monetary payoff for the alliance of $A$ and $B$ in the "2-1" contest is exactly the same as what $A$ and $B$ together would get in the "1-1-1" contest. The out-group player $C$ is better off in the "2-1" contest than in the "1-1-1" contest, but in the game considered he does not make a decision about which contest is played and is not our main focus of interest.

Our main research question compares exogenous alliances (NO CHOICE environment) to endogenously formed alliances (CHOICE environment). If the "2-1" subgame is reached, behavior within this subgame does not depend on the process that leads to the respective subgame, provided that players are motivated by their monetary payoffs only. In this case, the theoretical benchmark suggests: whether alliances are formed endogenously or exogenously is irrelevant for the players' behavior in the contest subgame. Additional motivations might, however, cause the process of alliance formation to have an impact on the equilibrium outcome in the contest subgame, and we will discuss potential effects after presenting the 
experimental design.

\subsection{Experimental treatments}

The "NO CHOICE" treatment serves as a baseline, and one interaction (round) proceeds as follows. In the first stage, the computer determines whether players $A, B$, and $C$ interact in a contest that follows the rules of the "1-1-1" contest as described in the theory section or whether $A$ and $B$ are teamed up in an alliance, leading to a contest interaction that follows the rules of the "2-1" contest. The subjects learn about this outcome and enter into stage 2 where all subjects simultaneously choose their contest effort as a nonnegative integer. The winner prize is $V=450$ tokens; the loser prize is zero. Subjects pay as many tokens as they have chosen as their "effort", irrespective of winning or losing. After all subjects in the group of three have chosen their efforts, they are shown the effort choices of all players in their group and a "fortune wheel" that determines the winning party. ${ }^{9}$ At the end of each round, subjects are displayed their own realized payoff from that round. Subjects participated in 15 independent and structurally identical interactions of this type where the "2-1" contest was selected in 10 out of the 15 rounds and the "1-1-1" contest was played in the remaining 5 rounds. The order of these contests was randomly chosen but was the same for all sessions. After each interaction, the subjects were randomly rematched.

The second treatment is the "CHOICE" treatment, which differs from the NO CHOICE treatment in only one aspect: the decision process in stage 1 that either leads to the formation of an alliance (subgame "2-1") or to stand-alone play by all players (subgame "1-1-1"). In the $C H O I C E$ treatment, players $A$ and $B$ are first asked independently and simultaneously whether they would like to form an alliance or to stand alone. If $A$ and $B$ both choose "1-1-1" or both choose "2-1", the subgame chosen is played. If $A$ and $B$ express diverging preferences, they are matched into an alliance with probability $1 / 2$ and stand alone otherwise. ${ }^{10}$ At the beginning of stage 2 , the decisions of players $A$ and $B$ are displayed to all three players $A$, $B$, and $C$ within a group. The subgame reached ("2-1" or "1-1-1") follows exactly the same rules as in the NO CHOICE treatment. Like the NO CHOICE treatment, the CHOICE treatment consists of 15 independent interactions with random rematching of subjects in

\footnotetext{
${ }^{9}$ The fortune wheel is a circle area with differently colored segments, whose size is proportional to the share of effort. A pointer spins clockwise and then stops in one of the segments to determine the winner. In the "1-1-1" contest, the fortune wheel consists of three segments, one for each player $A, B$, and $C$; in the "2-1" contest, there are only two segments: one for the alliance of $A B$ and another one for player $C$.

${ }^{10}$ An alternative rule could be that players only form an alliance if both $A$ and $B$ express this preference. In this case, there always exists the trivial equilibrium where both players decide not to form an alliance: independent of the own preference, this is a best response to the other player's decision to stand alone. Randomization in case of diverging preferences is a means to eliminate this (trivial) equilibrium and to incentivize subjects to state their true preference.
} 


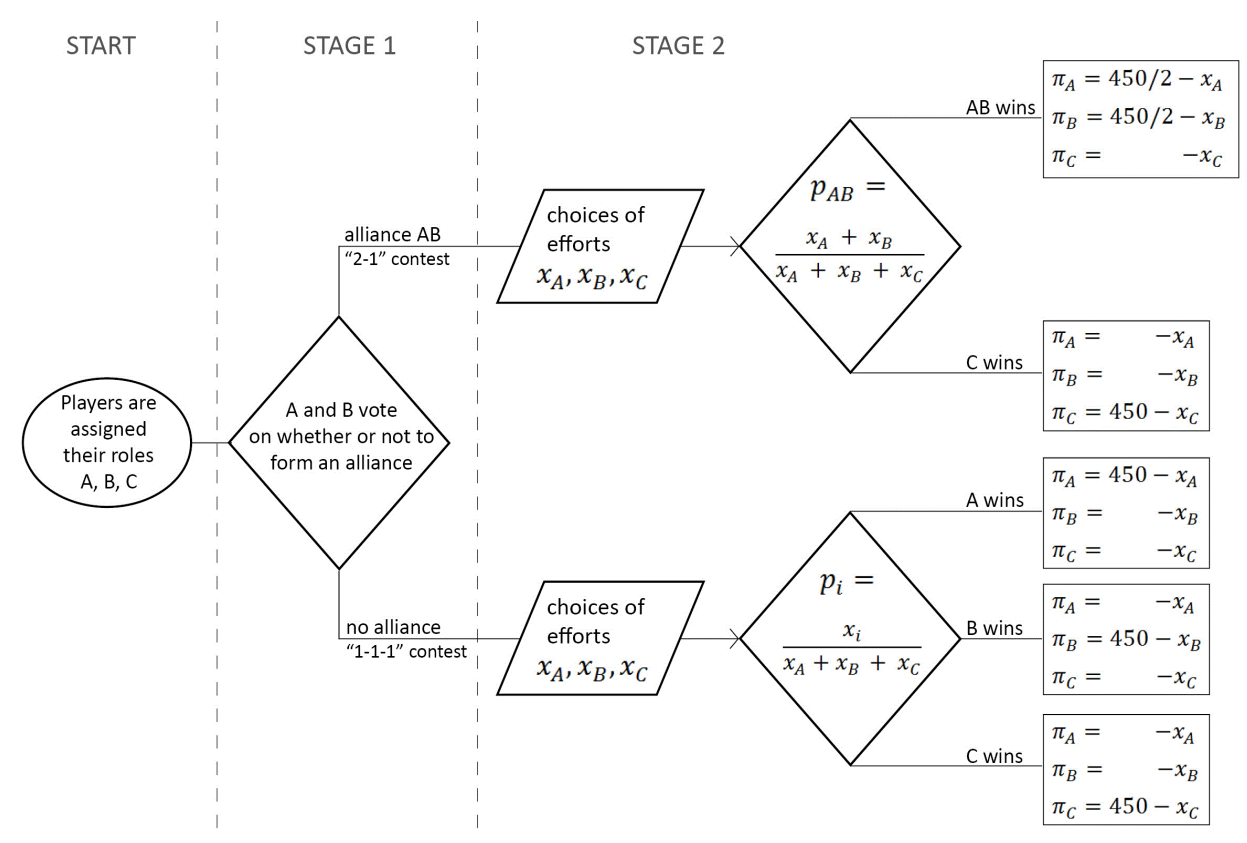

Figure 1: Sequence of actions in the CHOICE treatment.

each round. ${ }^{11}$ Figure 1 summarizes the sequence of events in the CHOICE treatment. (In the NO CHOICE treatment, Stage 1 in Figure 1 is replaced by a random device which selects the subgame.)

All subjects participated in 15 rounds of the NO CHOICE treatment and 15 rounds of the CHOICE treatment, keeping their role as player $A, B$, or $C$ throughout all 30 rounds. For half of the sessions, subjects started with the NO CHOICE treatment, followed by the CHOICE treatment; for the other half of the sessions, the order of NO CHOICE and CHOICE was reversed. ${ }^{12}$

\subsection{Experimental procedures}

To each of the computerized experimental sessions we typically admitted 18 subjects who were randomly assigned a fixed role ("player $A$ ", "player $B$ ", or "player $C$ ") at the beginning of the experiment. Then, the subjects were divided into groups of three players (consisting of one player of each role) and interacted exactly once before they were randomly regrouped, keeping their role as player $A, B$ or $C$. Although not having explicitly been stated in the

\footnotetext{
${ }^{11}$ The order in which the subgames are played now depends, of course, on the players' choices in the process of alliance formation.

${ }^{12}$ The rules of the first treatment to be played (CHOICE or NO CHOICE) were made common knowledge at the beginning of the experiment, and the rules for the second treatment were made common knowledge only after the first treatment had been completed. Initially, the subjects were told that the experiment would consist of two parts, but that the rules of the second part would only be announced after the end of the first part. A sample of the instructions is in Appendix B.5.
} 
experimental instructions, for the random matching we randomly divided the participants of a session into matching groups of 9 subjects in order to avoid dependencies between all observations of one session. Each subject had to go through the two treatments $C H O I C E$ and NO CHOICE outlined above.

The theory section revealed an indifference of players $A$ and $B$ between the choice of "1-1-1" and "2-1" if all players are motivated by monetary incentives only and assuming that alliance players play the symmetric equilibrium in the "2-1" contest. To break this indeterminacy, we introduced a small monetary incentive for the choice between the two subgames: In about one half of the sessions, players $A$ and $B$ each had to pay 5 tokens whenever the "2-1" contest was played; in the other half of the sessions, $A$ and $B$ each had to pay 5 tokens whenever the "1-1-1" contest was played. This small monetary incentive ( 5 tokens compared to the prize of 450 tokens) helps to ensure that players carefully consider their choice between the two games. The payment had to be made both in the $C H O I C E$ and in the $N O C H O I C E$ treatment, and it had to be made by both players $A$ and $B$, irrespective of their own choice. ${ }^{13}$ Hence, the variations in terms of sequence of play (NO CHOICE first or $C H O I C E$ first) and the small payment attached to one of the subgames (paying 5 tokens either for "2-1" or for "1-1-1") led to four different types of sessions, each consisting of the CHOICE and the NO CHOICE treatment. Each subject participated in exactly one of the four session types. ${ }^{14}$

The experiment took place at the University of Munich and was programmed using z-Tree (Fischbacher 2007). Overall, we conducted 17 sessions (3-5 sessions per session type) with a total of 231 subjects, mainly students. ${ }^{15}$ To ensure that subjects properly understood the rules of the game, they had to answer a set of pre-experimental questions. ${ }^{16}$ After having completed the respective rounds of both the CHOICE and the NO CHOICE treatments, subjects answered a set of postexperimental questions and took part in an incentivized one-shot prisoner's dilemma. Finally, each subject was paid separately and in private. A participant's payment consisted of (i) a EUR 4 show-up fee, (ii) his/her earnings in the

\footnotetext{
${ }^{13}$ Even if, from a theory perspective, this ex ante payment does not affect effort choices, it could have induced the subjects to feel a sunk-cost effect or an ex ante reduction of their endowment. Therefore, imposing the fee in both treatments reduces the possibility of a biased effort choice in the NOCHOICE versus the CHOICE treatment. Moreover, if the payment had, for instance, to be made for the "2-1" contest and only $A$ voted for the "2-1" contest, also $B$ had to pay 5 tokens in case "2-1" was realized. In this way we avoid that a player's choice depends on his beliefs about the co-player's choice; there is no incentive to vote in contradiction to the own preference, hoping to save the 5 tokens. Also, when entering the contest game, the alliance players $A$ and $B$ remain symmetric in terms of "sunk cost" or "budget".

${ }^{14}$ Table B.1 in the appendix summarizes the different session types.

${ }^{15}$ On average, subjects were 23.5 years old, about $28 \%$ had an economics background and $61 \%$ were females.

${ }^{16}$ At the beginning of the experiment all subjects first played two trial periods: one round of the "1-1-1" contest followed by one round of the "2-1" contest.
} 
prisoner's dilemma, (iii) a payment of EUR 0.60 for each of the 30 rounds (which essentially served as their endowment in the contest), and (iv) the profits (possibly negative) earned in 6 randomly selected rounds of the experiment. ${ }^{17}$ The exchange rate used in all sessions was 45 tokens $=$ EUR 1, that is, the value of the prize in a round selected for payment was equal to EUR 10. A session took about one and a half hours, and subjects earned an average of EUR 24 (with a standard deviation of EUR 10, a minimum of EUR 0 and a maximum of EUR 52.50) plus the show-up fee.

\subsection{Main predictions}

The fundamental question that motivates our analysis is on the determinants of alliance formation and alliance success. What explains a player's choice to form an alliance? What are the implications of self-selection into alliances for alliance success? To what degree does the ability of alliances to mobilize joint effort depend on the individuals' decision to form an alliance, compared to a situation where the alliance is formed by nature?

The main hypothesis that we want to test with the experimental data is motivated by a rational choice perspective on alliances: Average alliance effort is not affected by the process of alliance formation.

Hypothesis 1 In the "2-1" contest of the alliance $A B$ against the single player $C$, the average effort of an alliance player is the same in exogenously formed alliances and in voluntarily formed alliances.

If individuals are homogeneous and maximize their monetary payoffs, the data obtained in the experiment should provide evidence in favor of Hypothesis 1: Average alliance effort should be the same in the NO CHOICE treatment and the CHOICE treatment. ${ }^{18}$ There are, however, several effects that could cause effort to be dependent on the process of alliance formation. First, there could be a psychological effect of a conscious choice to form an alliance that is absent in the model outlined in appendix A.1. Being together in a voluntarily formed alliance may induce higher in-group solidarity, leading to a higher willingness to expend effort in order to increase the joint prospect of victory. Given the considerable evidence on in-group favoritism, the role that competing out-groups play for the behavior of players inside a group and the importance of building a group identity for in-group behavior, we

\footnotetext{
${ }^{17}$ At the end of the experiment, 3 out of the 15 rounds of each treatment were randomly drawn for payment. Bankruptcy of players was avoided by giving them a sufficiently high endowment.

${ }^{18}$ Note that Hypothesis 1 holds for all four session types, that is, independently of the order of play or the small payment that has to be made for one of the contest games.
} 
would expect behavior that systematically deviates from the irrelevance result summarized in Hypothesis $1{ }^{19}$

Second, there may be a correlation between individual-specific characterisitics - especially a player's willingness to expend effort - and the individual propensity to form an alliance. ${ }^{20}$ Thus, a difference between efforts in endogenous and exogenous alliances (and hence a rejection of Hypothesis 1) may also be driven by a selection of certain types of players into alliances. Concentrating on the selection issue, we set up two mutually exclusive testable statements which summarize the two possibilities that might emerge:

Hypothesis 2 a) Individuals who typically expend more-than-average effort are relatively more likely to enter into an alliance.

b) Individuals who typically expend less-than-average effort are relatively more likely to enter into an alliance.

If (some) players derive a non-monetary utility from winning and if this causes effort choices to be higher (Sheremeta 2010b), then players who are particularly keen on winning might choose to form an alliance because they expect their probability of winning to be higher in alliances. ${ }^{21}$ This would make players who typically expend higher-than-average effort more likely to form alliances (Hypothesis 2a), and self-selection of such "strong players" (in terms of their effort choice) would lead to higher efforts in endogenous alliances.

On the other hand, players who usually expend higher-than-average effort bear a larger share of the cost of alliance effort and therefore have a lower monetary payoff than their co-player in the alliance. These "strong players" might want to stay away from forming an alliance in order to avoid being "exploited" by their co-player. The subsample of players in endogenously formed alliances would then be made up of individuals who typically expend less-than-average effort (Hypothesis 2b), and the self-selection of players investing relatively little would make endogenously formed alliances less successful, compared to exogenously given alliances.

Finally, if individual effort is (positively or negatively) correlated with the individual preference for alliance formation, then players may take the other player's choice of alliance formation into account to update their beliefs about this player's type. The anticipation of the co-player's behavior may have an impact on the own effort choice. This might cause effort

\footnotetext{
${ }^{19}$ Moreover, there might be a purely psychological effect of giving players the option to select the game they would like to play.

${ }^{20}$ Individual-specific characteristics and their importance for players' effort levels in experimental contests between individuals have been analyzed by e.g., Price and Sheremeta (2012).

${ }^{21}$ Empirically, players $A$ and $B$ have a higher probability of winning in the "2-1" contest than in the "1-1-1" contest, although theoretically the probability of winning should be the same.
} 
in voluntarily formed alliances to be different from effort in exogenously formed alliances, wherein individuals cannot form beliefs about their co-player's type from stage 1 choices. Such strategic reactions to the co-player's decision on alliance formation will crucially depend on the evidence on Hypothesis 2.

In total, given these hypotheses, endogenous alliance formation may potentially evoke effects that work in opposite directions. Our data allow us to analyze the determinants of a player's choice to form an alliance and therefore to draw conclusions on the self-selection effect. In particular, to test the statements summarized in Hypothesis 2, we can examine the impact of an individual's average effort in the $N O C H O I C E$ treatment on this individual's decision for or against alliance formation in the $C H O I C E$ treatment. Here, average effort in the NO CHOICE treatment is used as a proxy for the effort that "the individual typically expends" in situations where this effort choice cannot be affected by the process of alliance formation.

In addition, with the data generated by the experiment, we can analyze various further questions on the behavior of players in voluntarily chosen three-player contests (the "1-1-1" contest), on the behavior of the single player $C$ (including a possible reaction of the single player $C$ to the nature of alliance formation, as the alliance players' choices on alliance formation are made common knowledge), and on the overall effect for contest outcomes.

\section{Results}

Our main hypothesis addresses the impact of alliance formation on contest behavior, comparing voluntarily formed to randomly formed alliances (CHOICE vs. NO CHOICE). Figure 2 illustrates time series of average effort by alliance players and stand-alone players in "2-1" contests. First of all, as known from other contest experiments, individuals expend more effort than theoretically predicted. ${ }^{22}$ This holds both for the alliance players and for the out-group player. ${ }^{23}$ Moreover, Figure 2 shows that average effort of players in voluntarily formed alliances is higher than average effort in randomly, and thus exogenously, formed alliances. This treatment effect of $C H O I C E$ is in contrast to the standard theory prediction

\footnotetext{
${ }^{22}$ Explanations for overdissipation and a high variability in efforts include spite and inequality aversion (Herrmann and Orzen 2008), non-monetary utility of winning (Sheremeta 2010b), risk preferences (Millner and Pratt 1991), endowment effects (Price and Sheremeta 2012), and mistakes (Potters et al. 1998).

${ }^{23}$ For alliance players, this overdissipation is reduced in later rounds; hence, average effort is lower in part 2 of the experiment, and this holds consistently for both treatments NO CHOICE and CHOICE. See also Table B.2 in the appendix, which summarizes average effort of alliance players in the $N O C H O I C E$ and in the $C H O I C E$ treatment, depending on the order in which these two treatments have been played.
} 


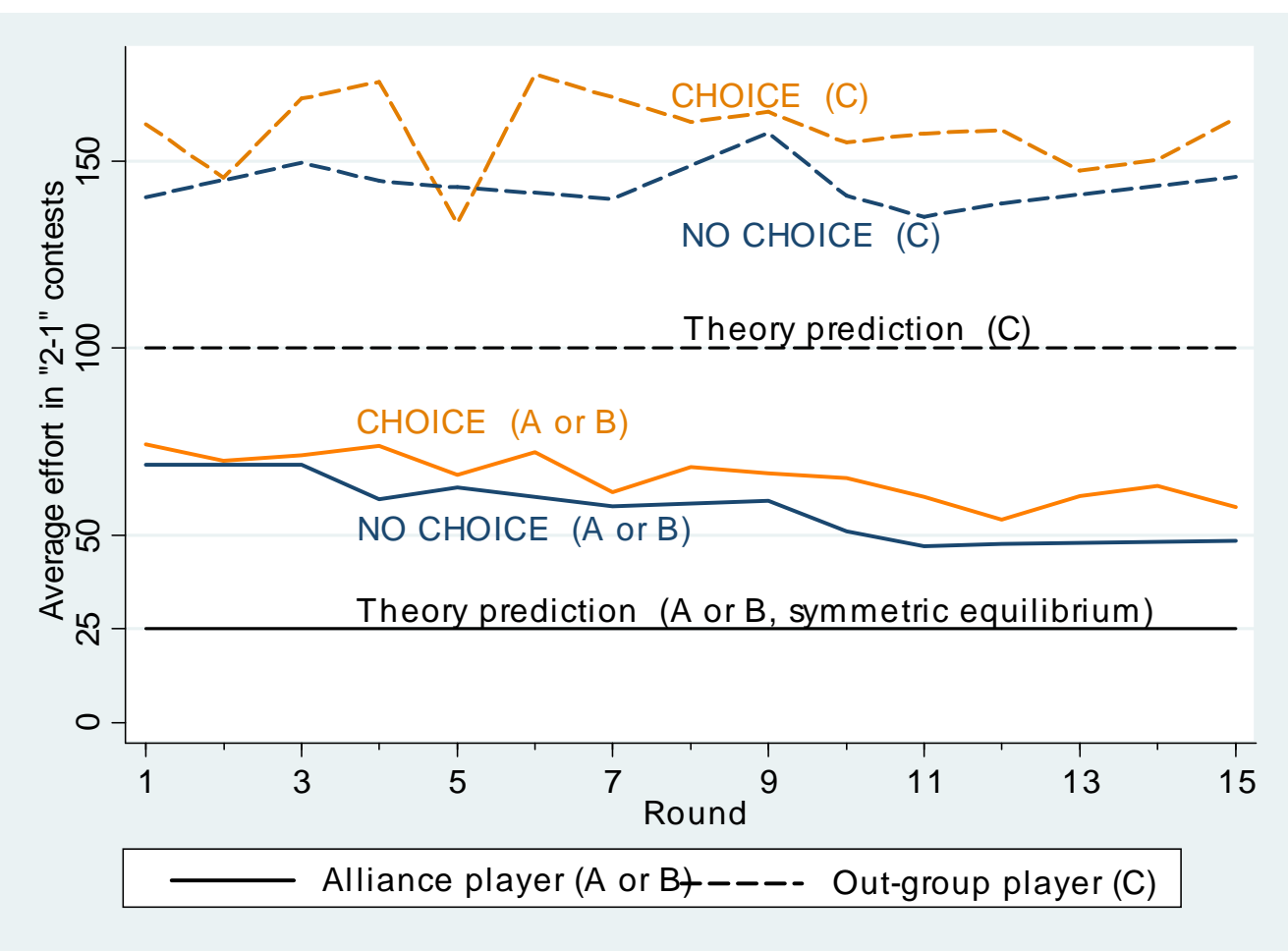

Figure 2: Individual effort in "2-1" contests.

in Hypothesis 1, and we will analyze this result in more detail below. ${ }^{24}$

It is also worth mentioning that, despite the increase in mobilized effort, voluntarily formed alliances are not more successful than exogenously formed alliances. Their probability of winning is almost the same in the CHOICE and in the NO CHOICE treatments (on average, $48.2 \%$ in $C H O I C E$ vs. $47.3 \%$ in $N O C H O I C E$ ). This is due to the higher average effort of the stand-alone player when facing voluntarily formed alliances (CHOICE) than when facing exogenously formed alliances (NO CHOICE). Because of the greater amount of effort expended, the monetary payoff of voluntarily formed alliances is lower than the payoff of randomly formed alliances (40.4 compared to 46.8).

\subsection{Decisions on alliance formation}

The difference in effort choices of voluntarily compared to randomly formed alliances can be caused by many factors; in particular, the observations for voluntarily formed alliances may not originate from the same sample of individuals as the observations for exogenously formed alliances. Instead, there may be several selection effects at work. Hence, before we turn to the analysis of individual effort choices, we examine the determinants of the choice

\footnotetext{
${ }^{24}$ It is important to note that this effect cannot be attributed to repeated games effects, as it occurs in a framework where individuals are randomly rematched in each round.
} 
of whether or not to form an alliance.

Table 1 presents the results of random-effects logistic regressions of a player $A$ or $B$ 's decision to form an alliance, $v_{i t}{ }^{25}$ The dependent variable is equal to 1 if, in round $t$, player $i \in\{A, B\}$ chooses to form an alliance and 0 otherwise. ${ }^{26}$ For all estimations in Table 1 , the vector of explanatory variables contains two dummy variables that control for the different session types we run: the variable "C-NC" indicates that the $C H O I C E$ treatment was played first and the dummy "PAY2-1" is equal to 1 whenever players $A$ and $B$ had to make a small payment in case the "2-1" contest was played. ${ }^{27}$

While the order of play does not significantly affect decisions on alliance formation, the probability of a vote for alliance formation is significantly lower whenever the small fee was applied to the "2-1" contest. To quantify the effect of the payment in terms of probabilities, the overall share of players $A$ and $B$ who vote for the "2-1" contest is $62.6 \%$ when the payment had to be made for "1-1-1" and $49.3 \%$ when the payment was applied to "2-1" (focusing on rounds 6-15). The small monetary incentives for or against alliance formation have worked in the predicted way, but have left scope for individual-specific characteristics to explain the propensity to enter into an alliance.

A focus of our interest is on individual-specific characteristics that explain the decision to join an alliance. From Estimation (2) onwards, we include socioeconomic information from the exit questionnaire as control variables; yet none of these variables significantly explain individual choices. ${ }^{28}$ In addition, the vector of explanatory variables contains an individual's effort levels in the contests of the NO CHOICE treatment in two different ways.

First, $\left(x_{i}-\bar{x}_{A, B}\right)_{N C}^{1-1-1}$ is an individual's average effort in the "1-1-1" contests of the NO CHOICE treatment, compared to the average effort of all players $A$ or $B$ in the "1-1-1" contests of the NO CHOICE treatment. ${ }^{29}$ Estimations (2) and (4) show that effort levels in exogenously selected "1-1-1" contests significantly influence the probability to vote for alliance formation. Players who typically contribute more than the average player $A$ or $B$ in

\footnotetext{
${ }^{25}$ The reported results focus on experienced behavior (rounds 6-15) to reduce the impact of learning. Including observations from all rounds into the estimation does, however, not qualitatively affect the results.

${ }^{26}$ Note that this does not imply that the "2-1" contest is played in this round since the selection of the contest variant also depends on the choice of the potential alliance partner.

${ }^{27}$ Recall that in half of the sessions the NO CHOICE treatment was played first and in the other half the order was reversed and that individual choices on alliance formation were incentivized by a small payment to be made for either the "2-1" or the "1-1-1" contest (each variant in about half of the sessions).

${ }^{28}$ The included variables are age, gender, field of study, number of siblings, height, and action chosen in the incentivized prisoner's dilemma played at the end of the experiment.

${ }^{29}$ This variable is computed exclusively from the observations of the NO CHOICE treatment in order to identify a player's "type" in situations where it cannot be affected by the preceding choice of the game. More specifically, it is an individual's average effort level in all "1-1-1" contests of the NO CHOICE treatment minus the average effort by all players $A$ or $B$ in all "1-1-1" contests of the NO CHOICE treatment (averaged over all sessions, i.e., independent of order and pay rule).
} 


\begin{tabular}{ccccc}
\hline \hline \multicolumn{4}{c}{$\begin{array}{c}\text { Dependent variable: choice of alliance formation } \\
\left(v_{i t}=1 \text { if choice }=" 2-1 ", i=A, B, t=\text { round }\right)\end{array}$} \\
\hline Indep. var. & xtlogit & xtlogit & xtlogit & xtlogit \\
& $(1)$ & $(2)$ & $(3)$ & $(4)$ \\
\hline Constant & $0.722^{*}$ & $0.898^{*}$ & $0.974^{*}$ & 0.797 \\
& $(0.412)$ & $(0.512)$ & $(0.523)$ & $(0.509)$ \\
C-NC & 0.396 & 0.483 & 0.377 & 0.478 \\
$(=1$ if CHOICE first $)$ & $(0.466)$ & $(0.465)$ & $(0.480)$ & $(0.474)$ \\
PAY2-1 & $-0.927^{* *}$ & $-0.826^{*}$ & $-0.860^{*}$ & $-0.790^{*}$ \\
$(=1$ if fee for "2-1" $)$ & $(0.466)$ & $(0.467)$ & $(0.478)$ & $(0.464)$ \\
& & & & $-0.008^{* *}$ \\
$\left(x_{i}-\bar{x}_{A, B}\right)_{N C}^{1-1-1}$ & & $-0.007^{* *}$ & & $(0.003)$ \\
$\left(x_{i}-\bar{x}_{A, B}\right)_{N C}^{2-1}$ & & $(0.003)$ & & 0.006 \\
& & & -0.001 & $(0.007)$ \\
$\left(\pi_{i}^{2-1}-\pi_{i}^{1-1-1}\right)_{N C}$ & & & & 0.004 \\
Socioeconomics & NO & YES & YES & YES \\
\hline Observations & 1540 & 1540 & 1540 & 1540 \\
Log likelihood & -751.73 & -747.83 & -750.71 & -747.54 \\
\hline \hline
\end{tabular}

Random-effects logistic regression (154 individuals), standard errors in parentheses, $* * *(* *, *)$ significant at the 1 percent level (5 percent, 10 percent). Observations from rounds 6-15 only (experienced behavior). Observations from "NO CHOICE first; fee for 1-1-1" are taken as the baseline group. "C-NC" and "PAY2-1" are control variables for the different session types; $\left(x_{i}-\bar{x}_{A, B}\right)_{N C}^{1-1-1}$ and $\left(x_{i}-\bar{x}_{A, B}\right)_{N C}^{2-1}$ are an individual's average efforts in the NO CHOICE treatment (in the "1-1-1" and the "2-1" contests, respectively), compared to the average effort of all players $A$ or $B$ in these contests. $\left(\pi_{i}^{2-1}-\pi_{i}^{1-1-1}\right)_{N C}$ is an individual's average payoff in "2-1" contests compared to his average payoff in "1-1-1" contests from the NO CHOICE treatment.

Table 1: Individual decision on alliance formation in the CHOICE phase. 
these contests are significantly less likely to choose alliance formation. This speaks in favor of Hypothesis 2b, rejecting Hypothesis 2a.

Second, $\left(x_{i}-\bar{x}_{A, B}\right)_{N C}^{2-1}$ is an individual's average effort in the "2-1" contests of the $N O$ CHOICE treatment, compared to the average effort of all players $A$ or $B$ in the "2-1" contests of the NO CHOICE treatment. An individual's average effort in the "2-1" contests is positively correlated with his effort in the "1-1-1" contests. However, Estimations (3) and (4) suggest that an individual's effort expended in exogenously formed alliances cannot explain the selection of players into endogenously formed alliances: the coefficient of $\left(x_{i}-\bar{x}_{A, B}\right)_{N C}^{2-1}$ is not significantly different from zero.

Result 1 a) Individuals who typically expend high effort in "1-1-1" contests are significantly less likely to form an alliance. b) Whether or not an individual typically expends high effort in the "2-1" contests does not significantly influence the likelihood of alliance formation.

The difference in Result 1 is quite intuitive: While effort in the "1-1-1" contests may reflect a subject's desire to win most closely, effort in the "2-1" contests may be affected by additional motivations. These may include solidarity with the fellow alliance partner or in-group favoritism more generally. Such in-group altruism in "2-1" contests might increase the probability of a vote for alliance formation and thus countervail the effect of higher commitment to expend effort.

As a further explanatory variable, Estimation (4) includes the difference between an individual's average payoff in the "2-1" contests and in the "1-1-1" contests of the NO CHOICE treatment. The estimated coefficient of this variable $\left(\pi_{i}^{2-1}-\pi_{i}^{1-1-1}\right)_{N C}$ is positive although only borderline significant ( $p$-value: 0.109): The higher the monetary advantage from playing the " $2-1$ " contest, the more likely it is that a player votes for the " $2-1$ " contest. ${ }^{30}$

The results on how a player's commitment to spend effort impacts decisions about alliance formation lead to an important conclusion: Higher efforts in voluntarily formed alliances cannot be a result of what could be called a 'direct selection effect'. The increase in efforts is not solely caused by players who typically expend high effort in "2-1" contests, selecting themselves into alliances in the CHOICE treatment.

\footnotetext{
${ }^{30}$ On average, players have a higher monetary payoff in the "2-1" contest than in the "1-1-1" contest; this can also explain the prevalent choice of the "2-1" contest. Moreover, players who typically choose higherthan-average effort have a smaller monetary advantage from actually choosing the "2-1" contest because they earn relatively more in the "1-1-1" contest, and they vote accordingly.
} 


\subsection{Effort of alliance players in "2-1" contests}

We now compare alliance players' effort in exogenous and voluntarily formed alliances. ${ }^{31}$ Table 2 shows the results of random-effects regressions of $x_{i t}$, the effort of an alliance player $i \in\{A, B\}$ in the "2-1" contest (in round $t$ ). All estimations include our main variable of interest, "CHOICE", which is equal to 1 in the CHOICE treatment and equal to 0 in the NO CHOICE treatment; "CHOICE" identifies whether the observed effort stems from voluntarily or from randomly formed alliances. Moreover, all four regressions include session controls. $^{32}$ Estimations (2)-(4) also control for socioeconomic characteristics as obtained from the exit questionnaire. ${ }^{33}$

Alliance players expend $9.6-9.7$ points more if the alliance emerges endogenously. The coefficient of "CHOICE" is significantly different from zero at the $1 \%$-level and robust throughout all estimations of the full sample (Estimations (1)-(3)) and to controlling for individual-specific characteristics. As the summary statistics have already suggested, endogenous alliance formation leads to an increased mobilization of efforts. ${ }^{34}$

Result 2 Individuals in voluntarily formed alliances contribute significantly more effort than individuals in randomly and exogenously formed alliances.

Note that the higher effort in endogenous alliances is not due to a selection of players, but occurs despite of such selection: High-effort types are more likely to stand alone; accordingly, fewer of them are members of an endogenously formed alliance than of an alliance that is randomly imposed on all players. ${ }^{35}$ The effect of higher effort in voluntary alliances outweighs a possible selection effect that tends to operate in the opposite direction.

\footnotetext{
${ }^{31}$ The reported results are again based on experienced behavior (rounds 6-15) and are robust to including observations from all rounds, using a tobit estimation to account for the truncation of effort levels at 0 , or estimating a multilevel mixed effects model to control for possible dependence at the level of matching groups.

${ }^{32}$ The session dummies included are again "C-NC" indicating that CHOICE was played first and "PAY21 " indicating that the incentivizing payment had to be made for the "2-1" contest. As Table 2 shows, neither the order of the treatments nor the fee to be paid for either of the games has a significant effect on effort choices.

${ }^{33}$ As before, the included variables are age, gender, field of study, number of siblings, height, and action chosen in an incentivized prisoner's dilemma played at the end of the experiment. None of these significanly affect effort levels in our experiment.

${ }^{34}$ This result is confirmed by a two-sided Wilcoxon signed-rank test that compares average alliance effort per matching group across the two phases (25 paired observations in total, p-value: 0.005). Figure B.3 in the appendix provides additional evidence on this treatment effect by showing that the distribution of alliance efforts in the $C H O I C E$ treatment first order stochastically dominates the distribution of alliance efforts in NO CHOICE.

${ }^{35}$ Table 2 shows: the higher individual effort in the "1-1-1" contests of NO CHOICE, the higher is the individual effort in "2-1" contests (compare the coefficient of $\left(x_{i}-\bar{x}_{A, B}\right)_{N C}^{1-1-1}$ ), but the lower is the probability to enter into an alliance (compare Table 1).
} 


\begin{tabular}{|c|c|c|c|c|}
\hline \multicolumn{5}{|c|}{$\begin{array}{c}\text { Dependent variable: individual effort } x_{i t} \text { of alliance players } A \text { and } B \\
\text { in the "2-1" contest (alliance } \mathrm{AB} \text { vs. player } \mathrm{C} \text { ) }\end{array}$} \\
\hline Indep. var. & $\begin{array}{l}\text { xtreg } \\
(1)\end{array}$ & $\begin{array}{l}\text { xtreg } \\
(2)\end{array}$ & $\begin{array}{l}\text { xtreg } \\
(3)\end{array}$ & $\begin{array}{l}\text { xtreg } \\
(4)\end{array}$ \\
\hline Constant & $\begin{array}{c}52.4^{* * *} \\
(5.09)\end{array}$ & $\begin{array}{c}51.1^{* * *} \\
(6.03)\end{array}$ & $\begin{array}{c}51.0 * * * \\
(6.02)\end{array}$ & $\begin{array}{c}55.1^{* * *} \\
(6.00)\end{array}$ \\
\hline $\begin{array}{c}\text { CHOICE } \\
(=1 \text { if CHOICE treatment })\end{array}$ & $\begin{array}{c}9.7^{* * * *} \\
(1.99)\end{array}$ & $\begin{array}{c}9.6^{* * *} \\
(1.99)\end{array}$ & $\begin{array}{c}9.6^{* * *} \\
(1.98)\end{array}$ & $\begin{array}{l}4.6^{* *} \\
(2.06)\end{array}$ \\
\hline $\begin{array}{c}\text { C-NC } \\
(=1 \text { if } \mathrm{CHOICE} \text { first })\end{array}$ & $\begin{array}{c}2.3 \\
(5.68)\end{array}$ & $\begin{array}{c}1.5 \\
(5.43)\end{array}$ & $\begin{array}{c}2.0 \\
(5.42)\end{array}$ & $\begin{array}{l}-4.5 \\
(5.44)\end{array}$ \\
\hline $\begin{array}{c}\text { PAY2-1 } \\
(=1 \text { if fee for "2-1") }\end{array}$ & $\begin{array}{c}-3.6 \\
(5.67)\end{array}$ & $\begin{array}{l}-3.7 \\
(5.44)\end{array}$ & $\begin{array}{l}-3.9 \\
(5.43)\end{array}$ & $\begin{array}{l}-6.0 \\
(5.45)\end{array}$ \\
\hline $\begin{array}{c}\left(x_{i}-\bar{x}_{A, B}\right)_{N C}^{1-1-1} \\
\left(x_{i}-\bar{x}_{A, B}\right)_{N C}^{1-1-1} \times \mathrm{CHOICE}\end{array}$ & & $\begin{array}{c}0.17^{* * *} \\
(0.03)\end{array}$ & $\begin{array}{c}0.13^{* * *} \\
(0.04) \\
0.09 * * * \\
(0.02)\end{array}$ & $\begin{array}{c}0.13^{* * *} \\
(0.04) \\
0.07^{* * *} \\
(0.03)\end{array}$ \\
\hline Socioeconomics & $\mathrm{NO}$ & YES & YES & YES \\
\hline $\begin{array}{c}\text { Observations } \\
\mathrm{R}^{2}\end{array}$ & $\begin{array}{c}1790 \\
0.0117\end{array}$ & $\begin{array}{c}1790 \\
0.0798\end{array}$ & $\begin{array}{c}1790 \\
0.0825\end{array}$ & $\begin{array}{l}1456^{\#} \\
0.0828\end{array}$ \\
\hline
\end{tabular}

Random-effects regression (154 individuals), standard errors in parentheses, ${ }^{* * *}\left(* *,{ }^{*}\right)$ significant at the 1 percent level (5 percent, 10 percent). Observations from rounds 6-15 only (experienced behavior). "CHOICE" indicates whether the observation stems from a voluntarily formed alliance; "C-NC" and "PAY2-1" are control variables for the different session types; $\left(x_{i}-\bar{x}_{A, B}\right)_{N C}^{1-1-1}$ is an individual's average effort in the "1-1-1" contests of the NO CHOICE treatment, compared to average effort of all players $A$ or $B$ in these contests. Observations from "NO CHOICE first; fee for 1-1-1" are taken as the baseline group.

\# Estimation (4) restricts observations in the CHOICE treatment to the subsample where both players A and $\mathrm{B}$ voted for alliance formation (i.e., $\left.\left(v_{i t}, v_{-i t}\right)=(1,1)\right)$.

Table 2: Alliance players' effort in the "2-1" contest. 
Estimation (3) provides additional information on who reacts most to the endogenous process of alliance formation. Individuals $A$ or $B$ who expend more-than-average effort in exogenously imposed "1-1-1" contests do not only expend more effort overall in "2-1" contests, but they also increase their effort more strongly in the CHOICE treatment: The interaction term of $\left(x_{i}-\bar{x}_{A, B}\right)_{N C}^{1-1-1}$ with the dummy "CHOICE" is significantly positive, suggesting that the treatment effect of "CHOICE" is stronger for those players who expend more-than-average effort in the "1-1-1" contests of the NO CHOICE treatment. High-effort subjects dislike forming an alliance, but if they end up in an alliance because their co-players want it, they react with strongly increasing their effort.

Result 3 Voluntary alliance formation leads to a stronger effort increase for those individuals who typically expend more-than-average effort in "1-1-1" contests and who typically prefer to stand alone.

As a direct consequence of this result, the treatment effect of "CHOICE" should be smaller when excluding the observations of voluntarily formed alliances where one of the alliance players voted against alliance formation, as done in Estimation (4). In this restricted sample of observations of unanimously formed alliances, the treatment effect of "CHOICE" becomes smaller (around 4.6 points) but is still significantly different from zero (at the 5\%level). The fact that effort in unanimously formed alliances is still higher than average effort in exogenously formed alliances (which include the high effort individuals) might be caused by a stronger feeling of in-group altruism in voluntarily formed alliances.

An additional explanation for the positive effect of endogenous alliance formation and, in particular, for the strong reaction of the individuals typically investing a lot is illustrated in Table 3. Here, average effort of alliance players in $C H O I C E$ is separated according to their own and their potential partner's votes on alliance formation, $v_{i t}$ and $v_{-i t}$ respectively. ${ }^{36}$

Table 3 shows that alliance members tend to increase their effort when their co-player voted for alliance formation (and presumably is a "low-effort type"): First, individuals who voted for alliance formation $\left(v_{i t}=1\right)$ choose higher effort if their co-player also decided to form an alliance than if their co-player voted against alliance formation (59.4 compared to 49.6). Hence, individuals react to their co-player's decision on alliance formation and adjust their effort choices accordingly. Facing a co-player who voted against alliance formation, individuals may anticipate that their fellow alliance member would choose a relatively high effort. This could explain why they expend less own effort if they are in an alliance with such co-players. Second, the highest effort in "2-1" contests is expended by individuals who

\footnotetext{
${ }^{36}$ Recall that, if $A$ and $B$ did not vote uniformly for or against an alliance, one of the two contest variants, "1-1-1" or "2-1", was randomly selected.
} 


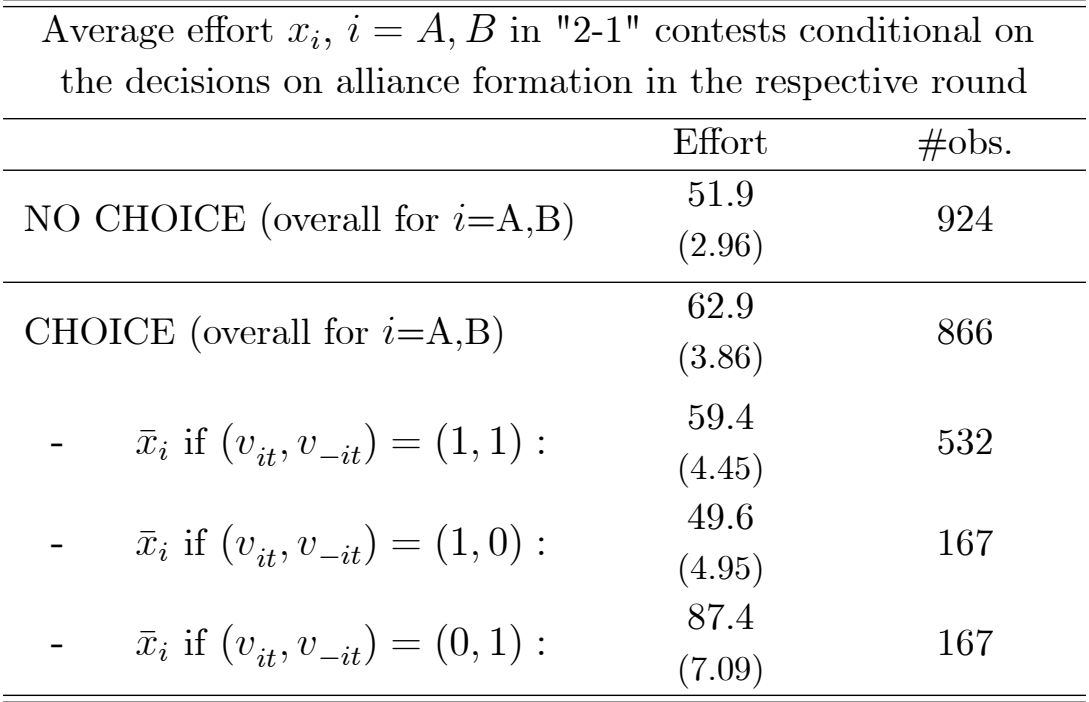

Calculated is the average effort of players $\mathrm{i}=\mathrm{A}, \mathrm{B}$ conditional on the own decision $v_{i t}$ and the co-player's decision $v_{-i t}$ on whether to vote for alliance formation $\left(v_{i t}=1\right.$ if, in round $\mathrm{t}$, i voted for the "2-1" contest). Observations from rounds 6-15 only. Standard errors in parentheses (clustered at the individual level).

Table 3: Alliance effort in the "2-1" contests conditional on the choices on alliance formation.

voted against alliance formation but ended up in an alliance because their co-player voted in favor of formation of an alliance (87.4 on average if $\left.\left(v_{i t}, v_{-i t}\right)=(0,1)\right)$.

If individuals who vote against alliance formation end up being in an alliance in the CHOICE treatment, they know that their co-player wanted to form an alliance - which seemingly goes hand-in-hand with lower effort levels. If the individuals are keen on winning and want to maintain their chances of winning, they have to make up for the lower effort of their co-player by increasing their own effort. Therefore, the increase in efforts by the individuals who voted against alliance formation can be interpreted as a behavior that accommodates to the co-player's anticipated behavior. Similar strategic reactions to the alliance players' votes in stage 1 can also be found for the out-group player, as we will see in the next section.

\subsection{Additional results on individual effort choices}

\subsubsection{Effort of stand-alone players in "2-1" contests}

In the following, we shortly examine how the (stand-alone) players $C$ react to the higher efforts of voluntarily formed alliances. Remember that the roles of the subjects were fixed throughout the experiment. Also recall that players $C$ have no influence on whether they fight against an alliance or against two single players. Hence, there is no selection effect for 
these stand-alone players. Estimating player $C$ 's effort choice in parallel to the estimations for the effort of players $A$ and $B$ (from Table 2), we find that $C$ 's effort against voluntarily formed alliances (CHOICE) is 13 points higher than $C$ 's effort against exogenously formed alliances; this increase is significant and robust throughout all estimations. ${ }^{37}$ (The regression results are in Table A.1 in the appendix.) ${ }^{38}$

Stand-alone players knew if the alliance they were facing was voluntarily formed (CHOICE), and they knew the alliance players' individual decisions on whether to form an alliance (there was complete information in the contest stage). If we separate player $C$ 's effort choice according to whether one or both of the alliance players voted for alliance formation, we find that the stand-alone player's effort is lower (by 14.2 points) when facing an alliance wherein both individuals had voted for alliance formation than when facing an alliance wherein one of the alliance members had voted for the "1-1-1" contest (compare the coefficient of " $I_{\left(v_{A, t}, v_{B, t}\right)=(1,1)} \times$ CHOICE" in Estimation 4 of Table A.1 in the appendix). Again, this behavior can constitute an optimal reply to the anticipated alliance effort which is highest in alliances that contain individuals who actually prefer to fight on their own.

\subsubsection{Effort of players $A$ or $B$ in "1-1-1" contests}

The experiment also reveals additional findings on contest behavior in three-player individual contests (the "1-1-1" contests). While the theory prediction for individual effort is 100, observed effort is considerably higher, in line with previous findings. Moreover, average effort of players $A$ and $B$ is higher when the "1-1-1" contest is played as a result of player $A$ and $B$ 's choice than when this scenario is randomly selected (155.6 compared to 136.0). ${ }^{39}$ This result can be seen as a straightforward selection effect. When players have the choice, those players who typically expend more-than-average effort in "1-1-1" contests are significantly more likely to vote for the stand-alone contest (compare the estimation results in Table 1).

Just as for the efforts in the "2-1" contest, we can separate average effort in the CHOICE treatment according to the individuals' decisions on alliance formation (see Table A.2 in the appendix). For those individuals who actually voted in favor of alliance formation (i.e., if $\left.v_{i t}=1\right)$, "1-1-1" efforts in the CHOICE treatment are lower compared to NO CHOICE

\footnotetext{
${ }^{37}$ Using a nonparametric Wilcoxon signed-rank test, however, the difference of player $C$ 's effort in the $N O$ CHOICE compared to the CHOICE treatment is insignificant (p-value: 0.1742).

${ }^{38}$ Those stand-alone players who invest more-than-average effort in "1-1-1" contests in NO CHOICE also invest more effort in the "2-1" contests. Again, individual efforts of a player $C$ in "1-1-1" and in "2-1" contests are positively correlated.

${ }^{39}$ Estimating effort of players $A$ and $B$ in the "1-1-1" contest similar to the estimations of the effort in "2-1" contests (as in Table 2) yields a coefficient of CHOICE of about +17 which is throughout significant at the 1\%-level. The p-value of a Wilcoxon signed-rank test testing this difference at the matching group level is 0.0283. Compare also the time series of efforts in "1-1-1" contests in Figure B.4 in the appendix.
} 
(114.6 compared to 136.0). For players who voted in favor of the "1-1-1" contest (i.e., if $\left.v_{i t}=0\right)$, "1-1-1" efforts are higher than the average effort in NO CHOICE. ${ }^{40}$ While the possibility to choose which contest to play also leads to increased efforts in "1-1-1" contests on the aggregate level, this effect is to a large extent caused by a selection of highly competitive individuals into these stand-alone contests.

\section{Conclusion}

Our analysis aimed at a better understanding of alliance formation in contests. Why are alliances formed and which factors determine whether an individual prefers to form an alliance or to stand alone? What are the implications of voluntary alliance formation on efforts and in-group solidarity? Key insights from our analysis are as follows.

(1) Players who are committed to expending amounts of effort that are much above average are inclined to stand alone. In this respect, our analysis is in line with the behavior of Friedrich Schiller's protagonist Wilhelm Tell: a "strong player" is stronger when standing alone than when he forms an alliance. The finding is also in line with the rational choice calculus of players who are willing to expend high effort. Players who have a higher subjective valuation of winning the contest anticipate that they will contribute more effort than others and that, in an alliance, other players inside their alliance may free-ride on them. This makes such "strong players" bear a disproportionately high share of the cost of alliance effort; hence, they prefer to stand alone. The other players who are less eager to expend much effort, however, benefit from this free-riding possibility.

(2) Whether players team up in an alliance on a voluntary basis or are forced to play as members of an alliance is important for their performance in the alliance. On average, players in a voluntary alliance expend more resources than players in a forced alliance. This result is obtained when comparing the efforts of players who self-select into an alliance and the efforts of players from the full sample who are forced into an alliance. We find that this higher effort in voluntary alliances is not a consequence of straightforward selection, but occurs even though there is a selection effect that downward-biases effort in the voluntary alliance. By (1), selection suggests that voluntary alliances are formed by players who expend comparatively little effort, whereas forced alliances consist of an unbiased sample of players. The higher efforts in voluntarily formed alliances are in line with results on in-group favoritism in psychology if one assumes that the voluntary association of an alliance has stronger group-formation power than the simple exogenous formation of alliances.

\footnotetext{
${ }^{40}$ Those individuals increase their effort even further when facing a co-player who would have preferred to play in an alliance (on average 189.0 if $v_{-i t}=1$ compared to 159.4 if $v_{-i t}=0$ ).
} 
(3) The effect of voluntary alliance formation is largest in alliances that only one of the alliance players voted for. The larger effect arises because those players who voted against alliance formation show a particularly strong reaction to playing in an endogenously formed alliance. In those endogenously formed alliances, a player's vote for or against alliance formation contains information about the individual willingness to expend effort. Consequently, the individuals who voted against alliance formation but end up in an alliance seem to correctly anticipate the lower effort choice of their fellow alliance member who voted for alliance formation; in order to compensate for this low effort and to keep their chances of winning high, they strongly increase their own effort. This high effort, however, is also anticipated by the alliance partners who, in turn, reduce their effort contribution. Similar strategic reactions can be observed on the part of the stand-alone players who, facing voluntarily formed alliances, increase their effort accordingly and who choose particularly high effort when fighting against an alliance wherein one of the players voted against alliance formation and subsequently chooses high effort.

Overall, we find evidence for higher in-group favoritism, causing alliance effort to be higher in voluntarily formed alliances. We also find that players who are willing to expend high effort correctly anticipate that they are exploited if in an alliance and prefer to stand alone. These findings have important implications for curbing or intensifying competition in contests and tournaments or, more specifically, for the design of work structures in labor markets. A contest designer interested in maximizing the total effort expended can best achieve this goal by preventing the formation of teams and letting the individuals interact as single players. However, a substantial share of individuals has shown to have a preference for competing in groups, even if alliance formation implies having to pay a fee. Taking this preference for alliance formation into account, it is advisable to let individuals choose freely whether or not to form groups. It strengthens their willingness to contribute to group success more than if the team structure is imposed on them. This holds despite the fact that voluntary group formation leads to a selection of less win-motivated individuals into the team. Moreover, as individuals understand this selection effect and react to it when choosing their own contribution, a contest designer who wants to elicit high effort choices may prefer to team up "weak" and "strong" individuals: In our experiment, the largest effect on group effort, i.e. the largest increase in contributions, has been observed in the "mixed" alliances where an individual who voted against alliance formation (over)compensated for the low (expected) effort of his co-player (compare Table 3; this also holds for total effort of all three players). Therefore, while participant involvement in the procedure of alliance formation leads to stronger in-group solidarity, a procedure that benefits such types of mixed group compositions may also be desirable when designing tournament environments. 


\section{References}

[1] Abbink, Klaus, Jordi Brandts, Benedikt Herrmann and Henrik Orzen, 2010, Intergroup Conflict and Intra-Group Punishment in an Experimental Contest Game, American Economic Review 100(1), 420-447.

[2] Ahn, T. K., R. Mark Isaac and Timothy C. Salmon, 2008, Endogenous group formation, Journal of Public Economic Theory 10(2), 171-194.

[3] Ahn, T. K., R. Mark Isaac and Timothy C. Salmon, 2009, Coming and going: Experiments on endogenous group sizes for excludable public goods, Journal of Public Economics 93(1-2), 336-351.

[4] Ahn, T. K., R. Mark Isaac and Timothy C. Salmon, 2011, Rent-seeking in Groups, International Journal of Industrial Organization 29, 116-125.

[5] Aimone, Jason, Laurence R. Iannaccone, Michael D. Makowsky and Jared Rubin, forthcoming, Endogenous Group Formation via Unproductive Costs, Review of Economic Studies.

[6] Altmann, Steffen, Armin Falk, and Matthias Wibral, 2012, Promotions and Incentives: The Case of Multi-Stage Elimination Tournaments, Journal of Labor Economics 30(1), $149-174$.

[7] Amaldoss, Wilfred, and Amnon Rapoport, 2005, Collaborative Product and Market Development: Theoretical Implications and Experimental Evidence, Marketing Science 24(3), 396-414.

[8] Amaldoss, Wilfred, and Amnon Rapoport, 2009, "Excessive Expenditures in Two-stage Contests: Theory and Experimental Evidence." In I. N. Hangen and A. S. Nilsen (Eds.), Game Theory: Strategies, Equilibria and Theorems, 241-266, Nova Science Publishers, NY.

[9] Amegashie, J. Atsu, Charles B. Cadsby, and Yang Song, 2007, Competitive burnout: Theory and experimental evidence, Games and Economic Behavior 59, 213-239.

[10] Baik, Kyung Hwan, and Sanghack Lee, 2001, Strategic groups and rent dissipation, Economic Inquiry 39(4), 672-684.

[11] Benenson, Joyce F., Henry Markovits, Melissa E. Thompson and Richard W. Wrangham, 2009, Strength determines coalitional strategies in humans, Proceedings of the Royal Society B: Biological Sciences 276, 2589-2595. 
[12] Bernhard, Helen, Urs Fischbacher and Ernst Fehr, 2006, Parochial altruism in humans, Nature 442(7105), 912-915.

[13] Bloch, Francis, 2012, Endogenous formation of alliances in contests, in: Oxford Handbook of the Economics of Peace and Conflict (eds.: M. Garfinkel and S. Skaperdas), Oxford University Press.

[14] Bloch, Francis, Santiago Sanchez-Pages and Raphael Soubeyran, 2006, When does universal peace prevail? Secession and group formation in conflict, Economics of Governance 7, 3-29.

[15] Brewer, Marilynn B., 1979, In-group bias in the minimal intergroup situation: A cognitive-motivational analysis, Psychological Bulletin 86(2), 307-324.

[16] Cason, Timothy N., William A. Masters and Roman M. Sheremeta, 2010, Entry into winner-take-all and proportional-prize contests: An experimental study, Journal of Public Economics 94(9-10), 604-611.

[17] Cason, Timothy N., Roman M. Sheremeta and Jingjing Zhang, 2012, Communication and efficiency in competitive coordination games, Games and Economic Behavior 76(1), 26-43.

[18] Chark, Robin, Amnon Rapoport and Rami Zwick, 2011, Experimental comparison of two multiple-stage contest designs with asymmetric players, Public Choice 147(3), 305329.

[19] Charness, Gary, Luca Rigotti, and Aldo Rustichini, 2007, Individual behavior and group membership, American Economic Review 97(4), 1340-1352.

[20] Charness, Gary, and Chun-Lei Yang, 2011, Public Goods Provision with Voting for Exclusion, Exit, and Mergers: An Experiment, Working Paper.

[21] Chen, Roy, and Yan Chen, 2011, The Potential of Social Identity for Equilibrium Selection, American Economic Review 101(6), 2562-2589.

[22] Chen, Yan, and Sherry Xin Li, 2009, Group Identity and Social Preferences, American Economic Review 99(1) 431-457.

[23] Cherry, Todd L., and Stephen J. Cotten, 2011, Sleeping with the enemy: The economic cost of internal environmental conflicts, Economic Inquiry 49(2), 530-539. 
[24] Cherry, Josh, Stephen Salant and Neslihan Uler, 2013, Experimental Departures from Self-Interest when Competing Partnerships Share Output, Working Paper.

[25] Dannenberg, Astrid, Andreas Lange and Bodo Sturm, 2010, On the formation of coalitions to provide public goods - experimental evidence from the lab, NBER working paper series, Working Paper 15967.

[26] Dechenaux, Emmanuel, Dan Kovenock and Roman M. Sheremeta, 2012, A Survey of Experimental Research on Contests, All-Pay Auctions and Tournaments, Working Paper.

[27] Dohmen, Thomas, and Armin Falk, 2011, Performance Pay and Multidimensional Sorting: Productivity, Preferences, and Gender, American Economic Review 101(2), 556590 .

[28] Eaton, B. Curtis, Mukesh Eswaran and Robert J. Oxoby, 2011, 'Us' and 'Them': the origin of identity, and its economic implications, Canadian Journal of Economics 44(3), 719-748.

[29] Ehrhart, Karl-Martin, and Claudia Keser, 1999, Mobility and cooperation: On the run,Working Paper.

[30] Eriksson, Tor, Sabrina Teyssier and Marie-Claire Villeval, 2009, Self-selection and the efficiency of tournaments, Economic Inquiry 47(3), 530-548.

[31] Esteban, Joan M., and József Sákovics, 2003, Olson vs. Coase: Coalitional worth in conflict, Theory and Decision 55(4), 339-357.

[32] Fischbacher, Urs, 2007, Z-tree: Zurich tool box for ready-made economic experiments, Experimental Economics 10(2), 171-178.

[33] Garfinkel, Michelle R., 2004, Stable alliance formation in distributional conflict, European Journal of Political Economy 20, 829-852.

[34] Goette, Lorenz, David Huffman and Stephan Meier, 2012a, The Impact of Social Ties on Group Interactions : Evidence from Minimal Groups and Randomly Assigned Real Groups, American Economic Journal: Microeconomics 4(1), 101-115.

[35] Goette, Lorenz, David Huffman, Stephan Meier and Matthias Sutter, 2012b, Competition Between Organizational Groups: Its Impact on Altruistic and Antisocial Motivations, Management Science 58(5), 948-960. 
[36] Gulick, Edward V., 1955, Europe's classical balance of power: a case history of the theory and practice of one of the great concepts of European statecraft, Cornell University Press for the American Historical Association.

[37] Herrmann, Benedikt, and Henrik Orzen, 2008, The appearance of homo rivalis: social preferences and the nature of rent seeking, University of Nottingham, Working Paper.

[38] Holmstrom, Bengt, 1982, Moral hazard in teams, Bell Journal of Economics 13(2), 324-340.

[39] Ke, Changxia, Kai A. Konrad and Florian Morath, 2012, Alliances in the shadow of conflict. Max Planck Institute for Tax Law and Public Finance Working Paper 2012-03.

[40] Ke, Changxia, Kai. A. Konrad and Florian Morath, 2013, Brothers in arms - An experiment on the alliance puzzle, Games and Economic Behavior 77(1), 61-76.

[41] Keser, Claudia and Claude Montmarquette, 2011, Voluntary versus Enforced Team Effort, Games 2, 277-301.

[42] Kimball, Anessa L., 2006, Alliance formation and conflict initiation: The missing link, Journal of Peace Research 43(4), 371-389.

[43] Konrad, Kai A., 2009, Strategy and Dynamics in Contests, Oxford University Press.

[44] Konrad, Kai A., 2011, Aspects of fighting in alliances, Working Paper of the Max Planck Institute for Tax Law and Public Finance No. 2011-09.

[45] Konrad, Kai A., and Dan Kovenock, 2009, The alliance formation puzzle and capacity constraints, Economics Letters 103, 84-86.

[46] Konrad, Kai A., and Florian Morath, 2012, Evolutionarily stable in-group favoritism and out-group spite in intergroup conflict, Journal of Theoretical Biology 306, 61-67.

[47] Kovenock, Dan, and Brian Roberson, 2012, Coalitional Colonel Blotto games with Application to the Economics of Alliances, Journal of Public Economic Theory 14(4), 653-676.

[48] Lazear, Edward P., and Sherwin Rosen, 1981, Rank-Order Tournaments as Optimum Labor Contracts, Journal of Political Economy 89(5), 841-864.

[49] Lazear, Edward P. and Kathryn L. Shaw, 2007, Personnel Economics: The Economist's View of Human Resources, Journal of Economic Perspectives 21(4), 91-114. 
[50] Li, Sherry Xin, Kutsal Dogan and Ernan Haruvy, 2011, Group identity in markets, International Journal of Industrial Organization 29, 104-115.

[51] Maynard Smith, John, 1974, The theory of games and the evolution of animal conflicts, Journal of Theoretical Biology 47, 209-221.

[52] Millner, Edward L., and Michael D. Pratt, 1991, Risk aversion and rent-seeking: An extension and some experimental evidence, Public Choice 69, 81-92.

[53] Morgan, John, Henrik Orzen and Martin Sefton, 2012, Endogenous entry in contests, Economic Theory 51(2), 435-463.

[54] Morgenthau, Hans Joachim, 1963, Politics among nations: the struggle for power and peace.

[55] Nalbantian, Haig R. and Andrew Schotter, 1997, Productivity Under Group Incentives: An Experimental Study, American Economic Review 87(3), 314-341.

[56] Nitzan, Shmuel, 1991, Collective rent dissipation, Economic Journal 101(409), 15221534.

[57] Olson, Mancur, and Richard Zeckhauser, 1966, An economic theory of alliances, The Review of Economics and Statistics 48(3), 266-279.

[58] Page, Talbot, Louis Putterman, and Bulent Unel, 2005, Voluntary association in public goods experiments: Reciprocity, mimicry and efficiency, Economic Journal 115(506), $1032-1053$.

[59] Parco, James E., Amnon Rapoport and Wilfred Amaldoss, 2005, Two-stage contests with budget constraints: An experimental study, Journal of Mathematical Psychology 49(4), 320-338.

[60] Potters, Jan C., Casper G. de Vries, and Frans van Winden, 1998, An experimental examination of rational rent seeking, European Journal of Political Economy 14, 783800.

[61] Price, Curtis R., and Roman M. Sheremeta, 2012, Endowment Origin, Demographic Effects and Individual Preferences in Contests, Working Paper.

[62] Sanchez-Pages, Santiago, 2007a, Endogenous coalition formation in contests, Review of Economic Design 11, 139-163. 
[63] Sanchez-Pages, Santiago, 2007b, Rivalry, Exclusion, and Coalitions, Journal of Public Economic Theory 9(5), 809-830.

[64] Schiller, Friedrich von, 1804, Wilhelm Tell, J. G. Cotta, Tübingen. Translation by Theodore Martin, 2007, Dodo Press.

[65] Shayo, Moses, and Asaf Zussman, 2011, Judicial ingroup bias in the shadow of terrorism, The Quarterly Journal of Economics 126, 1447-1484.

[66] Sheremeta, Roman M., 2010a, Expenditures and information disclosure in two-stage political contests, Journal of Conflict Resolution 54(5), 771-798.

[67] Sheremeta, Roman M., 2010b, Experimental comparison of multi-stage and one-stage contests, Games and Economic Behavior 68, 731-747.

[68] Sheremeta, Roman M., and Jingjing Zhang, 2010, Can groups solve the problem of over-bidding in contests?, Social Choice and Welfare 35(2), 175-197.

[69] Sherif, Muzafer, O.J. Harvey, B. Jack White, William R. Hood and Carolyn W. Sherif, 1961, Intergroup Conflict and Cooperation: The Robber Cave Experiment, Norman, Oklahoma: University Books.

[70] Skaperdas, Stergios, 1998, On the formation of alliances in conflict and contests, Public Choice 96, 25-42.

[71] Smith, Adam C., David B. Skarbek and Bart J. Wilson, 2012, Anarchy, Groups, and Conflict: An experiment on the emergence of protective associations. Social Choice and Welfare 38(2), 325-353.

[72] Sorokin, Gerald L., 1994, Arms, Alliances, and Security Tradeoffs in Enduring Rivalries, International Studies Quarterly 38(3), 421-446.

[73] Sutter, Matthias, 2009, Individual behavior and group membership: Comment, American Economic Review 99(5), 2247-2257.

[74] Sutter, Matthias, Stefan Haigner and Martin G. Kocher, 2010, Choosing the carrot or the stick? Endogenous institutional choice in social dilemma situations, Review of Economic Studies 77(4), 1540-1566.

[75] Sutter, Matthias, and Christina Strassmair, 2009, Communication, cooperation and collusion in team tournaments - An experimental study, Games and Economic Behavior $66(1), 506-525$. 
[76] Tajfel, Henri, 1982, Social psychology of intergroup relations, Annual Review of Psychology, 33, 1-39.

[77] Tajfel, Henri, and John Turner, 1979, An integrative theory of intergroup conflict, in: William Austin and Stephen Worchel (eds.), The Social Psychology of Intergroup Relations, Monterey, CA, Brooks/Cole Publ., 33-48.

[78] Tan, Guofu, and Ruqu Wang, 2010, Coalition formation in the presence of continuing conflict, International Journal of Game Theory 39, 273-299.

[79] Tullock, Gordon, 1980, Efficient rent seeking, Toward a theory of the rent-seeking society, 97-112. Texas A\&M University Press.

[80] Ursprung, Heinrich W., 1990, Public goods, rent dissipation, and candidate competition, Economics and Politics 2, 115-132.

[81] Waltz, Kenneth N., 1979, Theory of international politics. McGraw-Hill. 


\section{A Appendix}

\section{A.1 Equilibrium analysis}

The "1-1-1" contest. In the "1-1-1" contest, each player $i \in\{A, B, C\}$ chooses a nonnegative effort $x_{i}$; the choices are made simultaneously and independently. The vector of effort choices $\left(x_{A}, x_{B}, x_{C}\right)$ determines $i$ 's expected payoff as

$$
\pi_{i}^{1-1-1}=p_{i} V-x_{i}, i \in\{A, B, C\}
$$

Here, $p_{i}$ constitutes the probability that player $i \in\{A, B, C\}$ wins the contest, in which case he is attributed a prize of value $V$. With probability $1-p_{i}$ player $i$ does not win, and is attributed a prize of value zero. Independently of winning or losing the contest, player $i$ has to bear the cost of his own effort $x_{i}$, which is assumed to be equal to the effort itself (hence equal to $x_{i}$ ). Player $i$ 's probability of winning is

$$
p_{i}=\frac{x_{i}}{x_{A}+x_{B}+x_{C}}
$$

if $x_{A}+x_{B}+x_{C}>0$, and $p_{i}=1 / 3$ if all three contestants expend zero effort. ${ }^{41}$ The Nash equilibrium of this contest is known to be unique and characterized by effort choices

$$
\left(x_{i}^{1-1-1}\right)^{*}=\frac{2}{9} V, \quad i \in\{A, B, C\}
$$

and expected payoffs

$$
\left(\pi_{i}^{1-1-1}\right)^{*}=\frac{1}{9} V, \quad i \in\{A, B, C\}
$$

The "2-1" contest. In the "2-1" contest, players $A$ and $B$ are in alliance and compete against player $C$. As in "1-1-1", each player $i \in\{A, B, C\}$ chooses a nonnegative effort $x_{i}$, and all players choose their effort independently and simultaneously. The vector of action choices $\left(x_{A}, x_{B}, x_{C}\right)$ determines individual expected payoff as

$$
\begin{aligned}
& \pi_{i}^{2-1}=p_{A B} \frac{V}{2}-x_{i}, \quad i \in\{A, B\} \\
& \pi_{C}^{2-1}=\left(1-p_{A B}\right) V-x_{C}
\end{aligned}
$$

\footnotetext{
${ }^{41}$ This contest success function is used in many areas of economics, including marketing, rent-seeking, military conflict and sports competition. It has several axiomatic and microeconomic underpinnings. For a detailed review see Konrad (2009, Chapter 2.3).
} 
where the probability $p_{A B}$ that the alliance of $A$ and $B$ wins is defined as

$$
p_{A B}=\frac{x_{A}+x_{B}}{x_{A}+x_{B}+x_{C}}
$$

if $x_{A}+x_{B}+x_{C}>0$ and $p_{A B}=1 / 2$ otherwise. If the alliance wins, players $A$ and $B$ receive equal shares of the prize $V$; if player $C$ wins, he gets the full prize $V$. All losers get zero. By (3), the alliance's probability of winning depends on the sum of alliance members' efforts and not on the composition of $x_{A}+x_{B}$; alliance members' efforts are perfect substitutes when determining the alliance's win probability.

Nitzan (1991) showed that the equilibrium of this "2-1" contest is characterized by effort choices

$$
\left(x_{A}^{2-1}+x_{B}^{2-1}\right)^{*}=\frac{1}{9} V \text { and }\left(x_{C}^{2-1}\right)^{*}=\frac{2}{9} V
$$

and equilibrium payoffs

$$
\left(\pi_{A}^{2-1}+\pi_{B}^{2-1}\right)^{*}=\frac{2}{9} V \text { and }\left(\pi_{C}^{2-1}\right)^{*}=\frac{4}{9} V
$$

As the marginal cost of effort is constant and $p_{A B}$ depends on the sum of $x_{A}$ and $x_{B}$, only the sum of alliance players' efforts is uniquely determined in equilibrium. ${ }^{42}$

A comparison of (2) and (5) shows that the sum of the expected payoffs of $A$ and $B$ is the same in the "2-1" contest as in the "1-1-1" contest; the expected payoff of player $C$, however, is higher in the "2-1" contest.

\footnotetext{
${ }^{42}$ The first order condition for $i \in\{A, B\}$ is $\left(\partial p_{A B} / \partial x_{i}\right)(V / 2)=1$, where the left hand side only depends on $\left(x_{A}+x_{B}\right)$. Hence, for players $A$ and $B$, the "2-1" contest has multiple equilibria that differ in the individual payoff of the alliance players. Joint (and average) alliance effort, however, is identical in all equilibria.
} 


\section{A.2 Effort of stand-alone players in "2-1" contests}

\begin{tabular}{|c|c|c|c|c|}
\hline \multicolumn{5}{|c|}{$\begin{array}{c}\text { Dependent variable: individual effort } x_{C t} \text { of single player } C \\
\text { in the "2-1" contest (alliance } \mathrm{AB} \text { vs. player } \mathrm{C} \text { ) }\end{array}$} \\
\hline Indep. var. & $\begin{array}{l}\text { xtreg } \\
(1)\end{array}$ & $\begin{array}{l}\text { xtreg } \\
(2)\end{array}$ & $\begin{array}{c}\text { xtreg } \\
(3)\end{array}$ & $\begin{array}{l}\text { xtreg } \\
(4)\end{array}$ \\
\hline Constant & $\begin{array}{c}160.7^{* * *} \\
(16.12)\end{array}$ & $\begin{array}{c}150.4^{* * *} \\
(16.75)\end{array}$ & $\begin{array}{c}150.2^{* * *} \\
(16.81)\end{array}$ & $\begin{array}{c}150.9^{* * *} \\
(16.74)\end{array}$ \\
\hline $\begin{array}{c}\text { CHOICE } \\
(=1 \text { if CHOICE treatment })\end{array}$ & $\begin{array}{c}13.0^{* * *} \\
(4.74)\end{array}$ & $\begin{array}{c}13.0^{* * *} \\
(4.73)\end{array}$ & $\begin{array}{c}13.0^{* * *} \\
(4.73)\end{array}$ & $\begin{array}{c}21.4^{* *} \\
(6.38)\end{array}$ \\
\hline $\begin{array}{c}\mathrm{C}-\mathrm{NC} \\
(=1 \text { if } \mathrm{CHOICE} \text { first })\end{array}$ & $\begin{array}{l}-15.2 \\
(18.10)\end{array}$ & $\begin{array}{l}-15.3 \\
(14.87)\end{array}$ & $\begin{array}{l}-15.0 \\
(14.93)\end{array}$ & $\begin{array}{l}-15.3 \\
(14.86)\end{array}$ \\
\hline $\begin{array}{c}\text { PAY2-1 } \\
(=1 \text { if fee for "2-1") }\end{array}$ & $\begin{array}{c}-20.1 \\
(18.08)\end{array}$ & $\begin{array}{c}-10.9 \\
(15.03)\end{array}$ & $\begin{array}{l}-11.1 \\
(15.09)\end{array}$ & $\begin{array}{l}-11.9 \\
(15.03)\end{array}$ \\
\hline$\left(x_{i}-\bar{x}_{C}\right)_{N C}^{1-1-1}$ & & $\begin{array}{c}0.61^{* * *} \\
(0.11)\end{array}$ & $\begin{array}{c}0.58 * * * \\
(0.11)\end{array}$ & $\begin{array}{c}0.61^{* * *} \\
(0.11)\end{array}$ \\
\hline$\left(x_{i}-\bar{x}_{C}\right)_{N C}^{1-1-1} \times \mathrm{CHOICE}$ & & & $\begin{array}{c}0.06 \\
(0.07)\end{array}$ & \\
\hline$I_{\left(v_{A, t}, v_{B, t}\right)=(1,1)} \times \mathrm{CHOICE}$ & & & & $\begin{array}{c}-14.2^{*} \\
(7.26)\end{array}$ \\
\hline Socioeconomics & $\mathrm{NO}$ & YES & YES & YES \\
\hline Observations & 895 & 895 & 895 & 895 \\
\hline $\mathrm{R}^{2}$ & 0.0226 & 0.2702 & 0.2709 & 0.2691 \\
\hline
\end{tabular}

Note: Random-effects regression (77 individuals), standard errors in parentheses, ${ }^{* * *}\left({ }^{* *},{ }^{*}\right)$ significant at the 1 percent level ( 5 percent, 10 percent). Observations from rounds 6-15 only (experienced behavior). "CHOICE" indicates whether the observation stems from a contest against a voluntarily formed alliance; "C-NC" and "PAY2-1" are control variables for the different session types; $\left(x_{i}-\bar{x}_{C}\right)_{N C}^{1-1-1}$ is an individual's average effort in the "1-1-1" contests of the NO CHOICE treatment, compared to average effort of all players $C$ in these contests. The dummy variable $I_{\left(v_{A, t}, v_{B, t}\right)=(1,1)}$ indicates whether both alliance players had voted for alliance formation. Observations from "NO CHOICE first; fee for 1-1-1" are taken as the baseline group.

Table A.1: Stand-alone players' effort in the "2-1" contest. 


\section{A.3 Effort in "1-1-1" contests conditional on the choice of alliance formation}

\begin{tabular}{|c|c|c|}
\hline \multicolumn{3}{|c|}{$\begin{array}{l}\text { Average effort } x_{i}, i=A, B \text { in "1-1-1" contests conditional on } \\
\text { the decisions on alliance formation in the respective round }\end{array}$} \\
\hline & Effort & \#obs. \\
\hline NO CHOICE (overall for $i=\mathrm{A}, \mathrm{B}$ ) & $\begin{array}{l}136.0 \\
(6.51)\end{array}$ & 616 \\
\hline CHOICE (overall for $i=\mathrm{A}, \mathrm{B}$ ) & $\begin{array}{l}155.6 \\
(6.78)\end{array}$ & 674 \\
\hline$-\quad \bar{x}_{i}$ if $\left(v_{i t}, v_{-i t}\right)=(0,0):$ & $\begin{array}{l}159.4 \\
(9.34)\end{array}$ & 340 \\
\hline$-\quad \bar{x}_{i}$ if $\left(v_{i t}, v_{-i t}\right)=(0,1):$ & $\begin{array}{l}189.0 \\
(8.75)\end{array}$ & 167 \\
\hline$-\quad \bar{x}_{i}$ if $\left(v_{i t}, v_{-i t}\right)=(1,0):$ & $\begin{array}{l}114.6 \\
(8.30)\end{array}$ & 167 \\
\hline
\end{tabular}

Note: Calculated is the average effort of players $i=A, B$ conditional on the own decision $v_{i t}$ and the coplayer's decision $v_{-i t}$ on whether to vote for alliance formation $\left(v_{i t}=0\right.$ if, in round $t, i$ voted for the "1-1-1" contest). Observations from rounds 6-15 only. Standard errors in parentheses (clustered at the individual level).

Table A.2: Individual effort in the "1-1-1" contests conditional on the choices on alliance formation. 


\section{B Supplementary material}

\section{B.1 Session types}

\begin{tabular}{c|cc} 
& \multicolumn{2}{|c}{ Order of the two treatments: } \\
& NO CHOICE first & CHOICE first \\
\hline \hline Pay for "2-1" & $\begin{array}{c}\text { 6 independent observations } \\
54 \text { participants in total }\end{array}$ & $\begin{array}{c}6 \text { independent obs. } \\
57 \text { participants in total }\end{array}$ \\
\hline Pay for "1-1-1" & $\begin{array}{c}6 \text { independent observations } \\
54 \text { participants in total }\end{array}$ & $\begin{array}{c}7 \text { independent obs. } \\
\text { 66 participants in total }\end{array}$ \\
\hline \hline
\end{tabular}

Table B.1: Session specifications and number of observations.

\section{B.2 Alliance effort in "2-1" contests depending on the order of play}

\begin{tabular}{c|cccc}
$x_{A}$ or $x_{B}$ in "2-1" & Theory & Part 1 & Part 2 & Average \\
\hline \multirow{2}{*}{ NO CHOICE } & 25 & 55.4 & 48.8 & 51.9 \\
& & $(4.74)$ & $(3.64)$ & $(2.96)$ \\
CHOICE & 25 & 65.8 & 59.3 & 62.9 \\
& & $(4.96)$ & $(6.13)$ & $(3.86)$ \\
\hline$\Delta(\mathrm{CHOICE}-$ NO CHOICE $)$ & 0 & 10.3 & 10.5 & 11.0
\end{tabular}

Note: Observations from rounds 6-15 in each part only. The cells on the diagonal belong to the same session type ("No-Choice/Part 1" and "Choice/Part 2", for instance, belong to the "No Choice first" sessions). Standard errors in parentheses (clustered at the individual level).

Table B.2: Average effort of alliance players in the "2-1" contest.

This table summarizes average effort of alliance players in "2-1" contests, depending on the order in which the two treatments NO CHOICE and CHOICE were played. For observations from part 1 (that is, comparing treatments that were played first in the respective session), effort in $C H O I C E$ (if played first) is on average 10.3 points higher than in $N O$ CHOICE (if played first). Looking only at observations from part 2, efforts in CHOICE (if played second) are on average 10.5 points higher than in NO CHOICE (if played second). Finally, in both treatments, average efforts are consistently around 6.5 points lower in part 2 than in part 1 , due to learning effects. 


\section{B.3 Distribution of alliance effort in "2-1" contests}

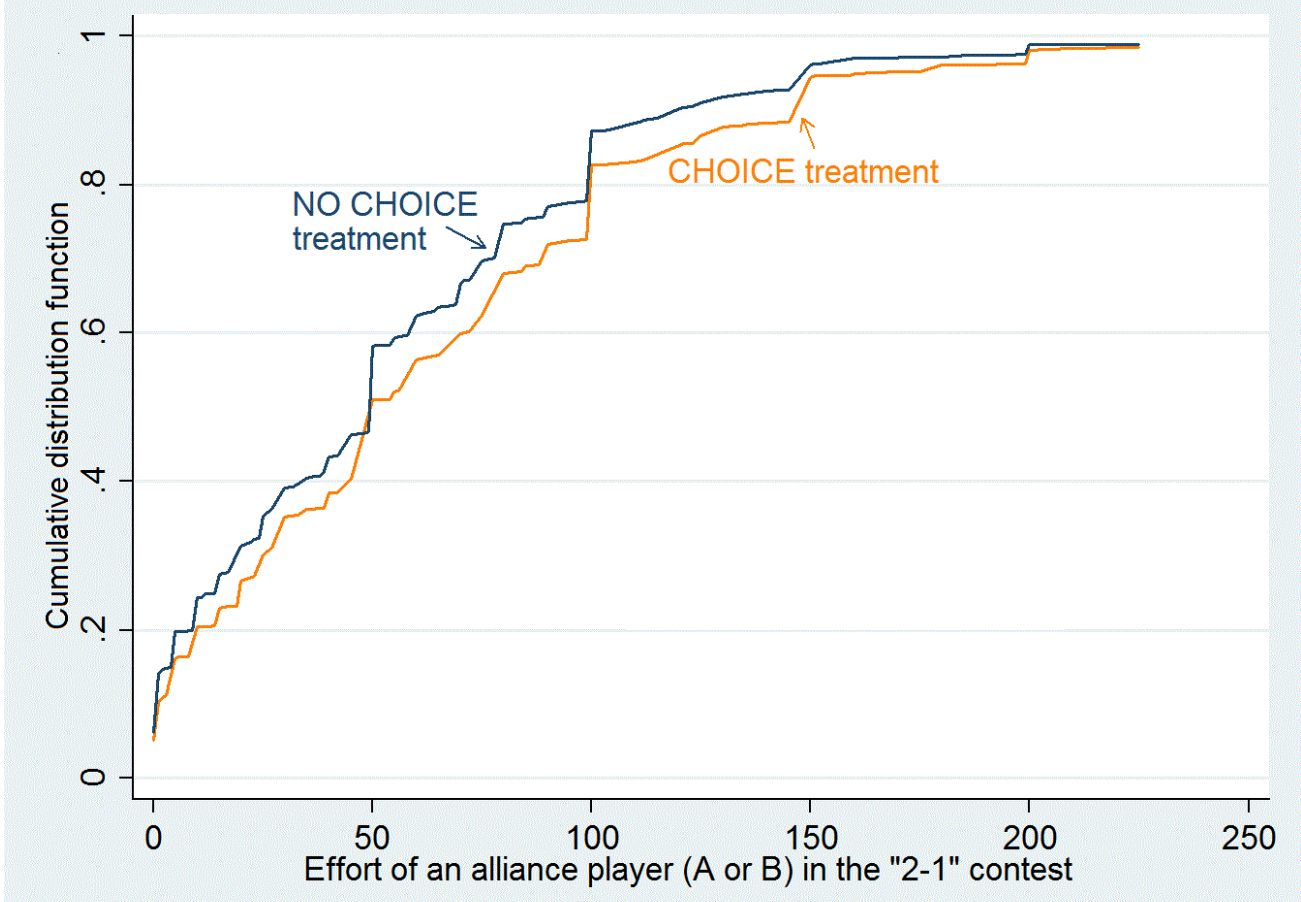

Figure B.3: Distribution of alliance effort in NO CHOICE and CHOICE.

Figure B.3 illustrates the cumulative distributions of effort by alliance players $A$ or $B$ in the "2-1" contest, comparing the CHOICE to the NO CHOICE treatment. (For the purpose of illustration, the domain of the functions is restricted to $x_{i} \in[0,225]$; a few outliers are dropped.) 


\section{B.4 Effort of players $A$ and $B$ in "1-1-1" contests}

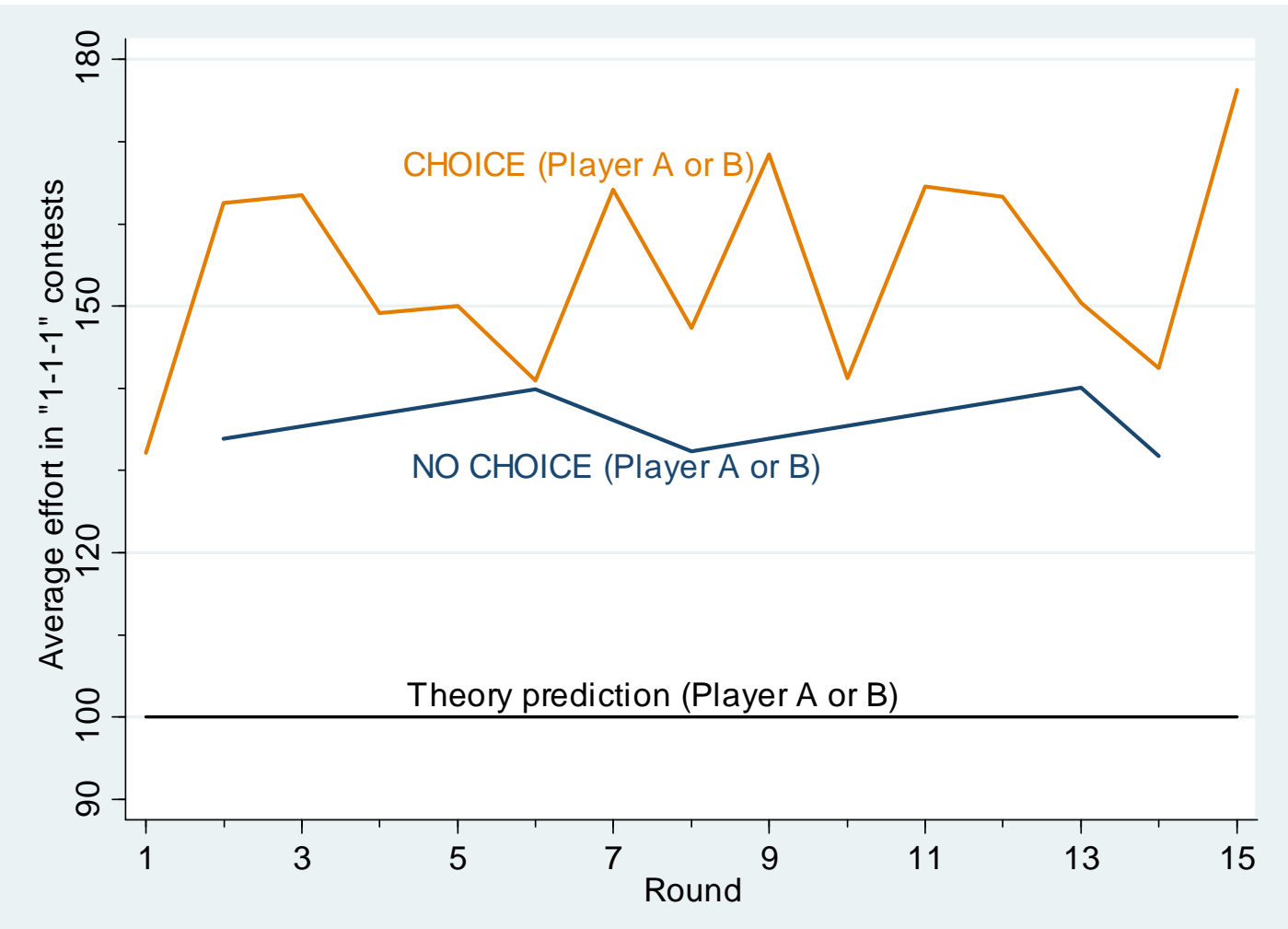

Figure B.4: Individual effort (of players $A$ or $B$ ) in "1-1-1" contests. 


\section{B.5 Experimental instructions ${ }^{1}$}

Welcome! Please read these instructions carefully and completely. Properly understanding them will help you to make better decisions and, hence, to earn more money.

Your earnings in this experiment will be measured in Tokens. At the end of the experiment we will convert the Tokens you have earned to cash and pay you in private. For each 45 Tokens you earn you will be paid 1 Euro in cash. In addition to the Tokens earned during the experiment, each participant will receive a show-up-fee of 4 Euros.

Please keep in mind that you are not allowed to communicate with other participants during the experiment. If you do not obey this rule you will be asked to leave the laboratory without getting paid. Whenever you have a question, please raise your hand and we will help you.

1. Your task Before beginning this experiment you will answer a quiz on your computer screen. It contains questions regarding situations which might occur during the experiment. Consulting these instructions will help you to answer them.

The experiment consists of three parts. These parts are independent from each other; your decisions in one part have no influence on the other parts.

For the experiment, groups consisting of three people are formed. The experiment will be repeated several times. The participants in your group will usually vary each period, since the groups are randomly composed in each period.

Your task in each period is to make an effort decision. The money you earn depends on your decision and the decisions of the other players in your group. Let the three players in one group be called A, B and C. In each period, three players A, B and C compete for a prize of 450 Tokens. The competition works through two options. These are called "Single" and "Alliance".

You will play both options during this experiment.

Following the quiz you will be able to try out both options in a trial period. The monitor will show you in each period which option is at hand.

The rules of both options are as follows:

Option "Single": The computer designates each player his role (A, B or C). All players will simultaneously choose their respective effort in Tokens. The effort affects the probability of winning the prize. Every player can choose any number of Tokens as effort. Tokens are not divisible, so you can only choose whole numbers, such as $0,1,2,3, \ldots$

You will have to pay this amount of Tokens to the lab, whether or not you win the competition.

\footnotetext{
${ }^{1}$ This section contains a translation of the set of instructions for the 2-PAY sessions where NO CHOICE was played first and CHOICE was played second. The instructions for the first part (here: NO CHOICE) were handed out in paper-form, and the instructions for the second part (here: $C H O I C E$ ) were shown on screen after completion of the first part.
} 
When all players have chosen their efforts, a fortune wheel will decide who will win the prize of 450 Tokens. The fortune wheel is divided into three colors: blue, green and purple. Blue represents the Tokens A has bet. Green represents the amount B has chosen, and purple C's amount.

The fractions of the colors on the fortune wheel correspond exactly to the proportion of the respective efforts to the total effort of all three players together.

All efforts of your group, and therefore the probability of each player to win the prize, will be presented to you for your information.

At the center of the fortune wheel there is an arrow initially pointing to the top. After some time the arrow starts to rotate and then stops randomly. If the arrow stops in the blue-colored area, player A wins. If the arrow stops in the green-colored area, player B wins the prize; If the arrow stops in the purple-colored area, player $\mathrm{C}$ wins the prize.

This means that the probability that player $\mathrm{A}, \mathrm{B}$ or $\mathrm{C}$ wins the prize is equal to his corresponding share of the effort in the total expense, hence

Probability that player $\mathrm{A}$ wins $=\frac{\text { effort of player A }}{\text { total expense of } \mathrm{A}, \mathrm{B} \text { and } \mathrm{C} \text { together }}$.

Analogous formulas apply for players B and C.

Therefore, each player's probability of winning depends not only on his own expenditure in the competition but also on the expenditures of the other players in the group.

Note that the more Tokens a player spends, the more likely it is that he wins the competition. More effort expended, however, also means that a player has to pay more Tokens to the lab.

If none of the players expend any Tokens, then it is equally likely (probability of $1 / 3 \mathrm{rd}$ ) that $\mathrm{A}$, or $\mathrm{B}$ or $\mathrm{C}$ wins.

As soon as at least one Token is bet, the above given formula for the probability of winning holds. If two players do not expend any Tokens, but the third player (e.g. B) expends at least one Token, the third player (i.e. B) wins the competition.

Every player has to pay his effort (in Tokens) to the lab, irrespective of the outcome of the fortune wheel.

Therefore, your earnings per period will be calculated as your prize in the competition minus your effort: earnings $=$ prize - effort.

The winning player gets the prize of 450 Token and the losing players get nothing. The winning player's earnings $=450$ - own effort, while the losing players have to pay their efforts to the lab and don't get any winnings.

Note: Should you bet more Tokens in a period than you can actually win, you will certainly make a loss.

The payment will only take place at the end of the entire experiment.

Option "Alliance": The two players A and B form an alliance. Player C is playing on his 
own.

Your role in the experiment, either A, B or C, will be randomly assigned to you. Each participant will keep his role throughout the entire experiment.

All players will simultaneously choose an effort (whole number), which they would like to bet. Each player decides independently on his effort. A player's effort can be any number of Tokens, which he will have to pay to the lab whether or not he wins the competition.

Players A and B have to pay 5 Tokens for every period they play in an "Alliance".

After the individual decisions have been made, a fortune wheel will turn and decide whether the alliance consisting of players $\mathrm{A}$ and $\mathrm{B}$ or player $\mathrm{C}$ wins the 450-Token-prize. As you will see, the fortune wheel is divided into two colors - turquoise and purple. The turquoise color represents the total Tokens spent by players A and B. The purple color represents the Tokens spent by player C.

For your information, you will be shown the amount of Tokens that the other players in your group have expended as well as the respective probabilities of $\mathrm{A}$ and $\mathrm{B}$, or $\mathrm{C}$ of winning the prize.

If the arrow stops in the turquoise-colored area, players $\mathrm{A}$ and $\mathrm{B}$ win the prize. If the arrow stops in the purple-colored area, player $\mathrm{C}$ wins the prize.

Probability that players $A$ and $B$ win the contest $=\frac{\text { effort of } A \text { and } B}{\text { sum of efforts of } A, B \text { and } C}$.

Probability that player $\mathrm{C}$ wins the contest $=\frac{\text { effort of player } \mathrm{C}}{\text { sum of efforts of } \mathrm{A}, \mathrm{B} \text { and } \mathrm{C}}$.

Therefore, each player's probability of winning depends not only on his own expenditure in the competition but also on the expenditures of the other players in the group.

If none of the players expend any Tokens then it is equally likely that the alliance consisting of players $\mathrm{A}$ and $\mathrm{B}$ or that player $\mathrm{C}$ wins.

As soon as at least one Token is bet, the above given formulas for the probability of winning hold.

Every player has to pay his effort (in Tokens) to the lab, irrespective of the outcome of the fortune wheel. Therefore, your earnings per period will be calculated as your prize in the competition minus your effort: earnings $=$ prize - effort.

If the alliance of $\mathrm{A}$ and $\mathrm{B}$ wins, each player receives only half of the prize. Their respective earnings are: 225 - 5 - own effort. Player $\mathrm{C}$ does not win anything but has to pay his effort.

If $\mathrm{C}$ wins, his earnings are his prize of 450 minus his own effort. Players $\mathrm{A}$ and $\mathrm{B}$ don't receive any earnings but have to each pay their respective effort plus 5 Tokens.

Note: Should you bet more Tokens in a period than you can actually win, you will certainly make a loss.

The payment will only take place at the end of the entire experiment. 
2. Procedure The experiment will consist of 15 periods. In each period, you will have the same role (player A, B or C). The other two players in your group will be randomly assigned to you in each period.

Player C always plays alone. Players A and B either play alone or in an alliance, depending on the game option (Single or Alliance). The two players in your group will be randomly assigned to you in each period. You will not know who the other players in your group are. Any attempt to reveal your identity to anyone is prohibited.

At the end of today's experiment, we will randomly choose 3 periods out of 15 ; your total earnings in those 3 periods will be added up, converted to Euros and paid to you in cash. This means that the earnings of all other 12 periods will not be paid to you and that you do not have to pay your efforts from those periods either. You will get to know which 3 out of the 15 periods will be chosen only at the end of this experiment. In addition, you will receive 0.60 Euros for each of the 15 periods.

You will receive information about the second and third parts of the experiment on your screen. After the experiment, you will be asked to answer some questions, including some personal information (e.g., gender, age, major...). All the information you provide will be kept anonymous and strictly confidential.

We will begin now with the quiz, after which you will have the opportunity to try playing one Single and one Alliance game. We would like to thank you in advance for participating and wish you good luck!

Part $2^{2}$ This part will consist of 15 periods.

In each period, players A and B will vote on whether they would like to play option Single or option Alliance.

- If player A and player B both choose Single, option Single will be played.

- If player A and player B both choose Alliance, option Alliance will be played.

- If each option receives one vote, there will be a random draw. The options are then chosen with equal probability.

\footnotetext{
${ }^{2}$ The instructions for the second part were displayed on the screen. This sample is for the sessions where the small fee was applied to the "2-1" contest and where NO CHOICE was played first. Hence, Part 2 refers to the CHOICE treatment.
} 
At all times, the screen will keep you informed about which option was picked for the period you are in.

- If option Alliance is realized, player A and player B will each have to pay 5 additional tokens to the laboratory. Player $\mathrm{C}$ does not have to pay any additional tokens.

- If option Single is realized, no additional payment from anyone is incurred.

All other rules, as described in the instructions, remain in place.

Three out of the following 15 periods will be chosen for payment. In addition, you will receive 0.60 Euros for every period in this part. 